OPEN ACCESS

Edited by:

Rudolf Lucas,

Augusta University, United States

Reviewed by:

Denise D. Belsham,

University of Toronto, Canada

Hugo Caire Castro-Faria-Neto,

Fundação Oswaldo Cruz (Fiocruz),

Brazil

*Correspondence:

Djurdjica Coss

djurdjica.coss@ucr.edu

Specialty section: This article was submitted to Inflammation,

a section of the journal

Frontiers in Immunology

Received: 04 June 2018 Accepted: 13 August 2018

Published: 11 September 2018

Citation:

Lainez NM, Jonak CR, Nair MG, Ethell IM, Wilson EH, Carson MJ and Coss D (2018) Diet-Induced Obesity Elicits Macrophage Infiltration and Reduction in Spine Density

in the Hypothalami of Male but Not Female Mice.

Front. Immunol. 9:1992.

doi: 10.3389/fimmu.2018.01992

\section{Diet-Induced Obesity Elicits Macrophage Infiltration and Reduction in Spine Density in the Hypothalami of Male but Not Female Mice}

\author{
Nancy M. Lainez, Carrie R. Jonak, Meera G. Nair, Iryna M. Ethell, Emma H. Wilson, \\ Monica J. Carson and Djurdjica Coss*
}

Division of Biomedical Sciences, School of Medicine, University of California, Riverside, Riverside, CA, United States

Increasing prevalence in obesity has become a significant public concern. C57BL/6J mice are prone to diet-induced obesity (DIO) when fed high-fat diet (HFD), and develop chronic inflammation and metabolic syndrome, making them a good model to analyze mechanisms whereby obesity elicits pathologies. DIO mice demonstrated profound sex differences in response to HFD with respect to inflammation and hypothalamic function. First, we determined that males are prone to DIO, while females are resistant. Ovariectomized females, on the other hand, are susceptible to DIO, implying protection by ovarian hormones. Males, but not females, exhibit changes in hypothalamic neuropeptide expression. Surprisingly, ovariectomized females remain resistant to neuroendocrine changes, showing that ovarian hormones are not necessary for protection. Second, obese mice exhibit sex differences in DIO-induced inflammation. Microglial activation and peripheral macrophage infiltration is seen in the hypothalami of males, while females are protected from the increase in inflammatory cytokines and do not exhibit microglia morphology changes nor monocyte-derived macrophage infiltration, regardless of the presence of ovarian hormones. Strikingly, the anti-inflammatory cytokine IL-10 is increased in the hypothalami of females but not males. Third, this study posits a potential mechanism of obesity-induced impairment of hypothalamic function whereby obese males exhibit reduced levels of synaptic proteins in the hypothalamus and fewer spines in $\mathrm{GnRH}$ neurons, located in the areas exhibiting macrophage infiltration. Our studies suggest that inflammation-induced synaptic remodeling is potentially responsible for hypothalamic impairment that may contribute to diminished levels of gonadotropin hormones, testosterone, and sperm numbers, which we observe and corresponds to the observations in obese humans. Taken together, our data implicate neuro-immune mechanisms underlying sex-specific differences in obesity-induced impairment of the hypothalamic function with potential consequences for reproduction and fertility.

Keywords: sex-specific, cytokine, GnRH, neuroinflammation, obesity, hypothalamus 


\section{INTRODUCTION}

Over half of the US population is classified as overweight and a full third is classified as obese (1). The number of obese people has increased steadily over the last 30 years (2). This increase in obesity has coincided with an increase in comorbidities, such as type 2 diabetes, cardiovascular disease, stroke, and hypothalamic disorders, including reproductive disorders that cause infertility (3-6). Deleterious effects of obesity on fertility include irregularities in menstrual cycles, abnormalities in the oocyte development, anovulation, and increased risk of miscarriages in women (3); and inferior sperm quality, reduced sperm quantity, and lower testosterone levels in men (7). Currently, $18 \%$ of couples require assisted reproductive technologies to become pregnant (8), a portion of which may stem from widespread obesity $(9,10)$. Although several hypotheses have been put forth (11-15), mechanisms whereby obesity negatively affects reproductive function are unknown.

The hypothalamus in the basal forebrain controls feeding and satiety, thermoregulation, thirst, circadian rhythms, metabolism, and mammalian reproduction. In the control of reproduction, the hypothalamic decapeptide gonadotropin-releasing hormone $(\mathrm{GnRH})$ is the final brain output that regulates expression and secretion of gonadotropins, luteinizing hormone (LH) and follicle stimulating hormone (FSH) from the anterior pituitary gonadotropes (16), which in turn stimulate steroidogenesis and gametogenesis in the gonads $(17,18)$. In the rodent hypothalamus, the majority of $\mathrm{GnRH}$ cell bodies are scattered in the preoptic area surrounding organum vasculosum laminae terminalis (OVLT), while secretion occurs at the terminals in the median eminence (ME). Both OVLT and ME are circumventricular areas with a leaky blood-brain barrier, whereby hypothalamic neurons perceive changes in the circulation and neuropeptides reach the portal circulation (19). GnRH secretion is synchronized by upstream regulatory neuronal populations (20). These regulatory neurons integrate sex steroid feedback from the gonads (21), and external or environmental factors, such as stress $(22,23)$, and exposure to endocrine disruptors $(24,25)$. Metabolic stimuli and energy status, such as anorexia nervosa, excessive exercise, malnutrition, and obesity are also integrated with reproductive function at the level of the hypothalamus (11$13,15,26,27)$. However, since metabolic signals do not influence GnRH neurons directly (28-30), we investigated other potential mechanisms.

Obesity is characterized by chronic inflammation, in addition to changes in metabolic markers (31). Increased adiposity elicits an increase in inflammatory cytokines in the circulation $(32,33)$, such as: tumor necrosis factor (TNF $\alpha)$, and interleukins, IL-1 $\beta$, IL-6 (34), primarily due to macrophage infiltration to adipose tissue and their subsequent activation. Inflammatory cytokines have been demonstrated to negatively affect reproductive function (35). Influence of acute inflammation on reproduction was an area of intense investigation and these studies determined that LPS or cytokine administration in the brain ventricle reduces gonadotropin levels, diminishes GnRH neuropeptide release and represses $\mathrm{GnRH}$ and $\mathrm{LH}$ gene expression (36-38). As opposed to the acute, high level of inflammatory cytokines used in previous studies, obesity elicits low grade, chronic inflammation and we investigated its effects on reproduction via $\mathrm{GnRH}$ neurons.

To analyze the effects of obesity-induced inflammation on reproductive function we used diet-induced obese (DIO) mice. Significant strain differences were observed in response to high-fat diet (HFD) and A/J, FVB/NJ and BALB/cJ strains are resistant to $\mathrm{DIO}$, while $\mathrm{DBA} / 2 \mathrm{~J}$ and $\mathrm{C} 57 \mathrm{BL} / 6 \mathrm{~J}$ gain weight (39-41). The C57BL/6J mouse is a particularly faithful model of the human metabolic syndrome because it develops obesity, hyperinsulinemia, hyperglycemia, and hypertension, when allowed ad libitum access to a HFD (42, 43). Herein, we demonstrate profound sex differences in response to HFD. Specifically, C57BL/6J male mice exhibit neuroinflammation, with a resultant decrease in the number of synaptic spines on GnRH neurons and reduction in GnRH mRNA levels. On the other hand, female mice are resistant to neuroendocrine and inflammatory changes, and this protection is independent of ovarian hormones. Together, our data implicate sex-specific effects in obesity-induced neuroinflammation with functional consequences on GnRH neurons.

\section{MATERIALS AND METHODS}

\section{Animals}

C57BL/6J mice were obtained from Jackson Laboratory at 3 weeks of age. After a week acclimatization, they were randomly assigned to the high-fat diet fed group (HFD, D12492, 60\% kcal from fat; Research Diet, New Brunswick, NJ) and control group (Ctr, D12450J, 10\% kcal; Research Diet, New Brunswick, NJ) for an indicated number of weeks. Animals were maintained under a 12-h light, 12-h dark cycle and received food and water ad libitum. All experiments were performed with approval from the University of California Animal Care and Use Committee and in accordance with the National Institutes of Health Animal Care and Use Guidelines using 16-week-old animals (3 weeks before weaning, 1 week normal chow, 12 weeks high fat or control diet) unless indicated otherwise. During the week between weaning and experimental diet, while fed normal chow, all animals were handled daily by experienced personnel to assure habituation and minimize stress (44).

For fluorescently labeled microglia, CX3CR1-GFP mice were obtained from Jackson labs (strain 005582) and randomly placed on the respective diets at 4 weeks of age to analyze change in microglia morphology. Doubly fluorescent GFP and RFP transgenic mice obtained after crossing CX3CR1-GFP (strain 005582) and CCR2-RFP (strain 017586), and heterozygous mice for both alleles were used to distinguish monocyte recruitment to the hypothalamus from resident microglia. GnRH-GFP mice were kindly provided by Dr. Suzanne Moenter (45). Males and females were analyzed separately to determine sex differences. At least 10 animals per sex per genotype were analyzed, unless indicated otherwise for a specific analysis in the materials and methods section. Statistical differences $(p<0.05)$ between control (Ctr) and high fat diet (HFD) fed mice were determined by Student's T-test or 2-way ANOVA where appropriate, and Tukey's test for multiple comparison. 


\section{Estrous Cyclicity}

Starting at 12 weeks of the Ctr or HFD, female mice were assessed for estrous cycle stage with daily vaginal smears for 6 weeks. Vaginal lavage was performed daily (between 9-10 am) by flushing the vagina with distilled $\mathrm{H}_{2} \mathrm{O}$. Collected smears were mounted on glass slides and examined microscopically for cell types. Both groups of animals were handled daily, at the same time of day, to account for any potential stress that handling may cause. Estrous cycle stages determined during the first week of vaginal smears were not included in the analysis to allow for acclimatization. Female mice on control diet exhibited normal 4-5 day-long estrous cycles, indicating habituation to handling. Estrous cycle length was calculated as the length of time between two successive occurrences of estrus. For subsequent studies, females were estrous cycle staged and tissue samples collected in diestrus between 9 and 11 a.m.

\section{Sperm Count}

After 12 weeks on the respective diet, males were sacrificed between 9 and $11 \mathrm{a} . \mathrm{m}$. The epididymides were dissected, macerated, and then incubated in $1 \mathrm{ml}$ DMEM at room temperature for $30 \mathrm{~min}$ with shaking. Sperm was cleared with a $70 \mu \mathrm{m}$ cell strainer, diluted with sterile water and counted with a hemocytometer.

\section{Cytokine and Hormone Analyses}

For serum collection, mice were sacrificed between 9 and 11 a.m. by isoflurane inhalation and blood was obtained from the inferior vena cava. The blood was left to coagulate for $15 \mathrm{~min}$ at room temperature, and then centrifuged at 2000 RCF for $15 \mathrm{~min}$ for serum separation. Cytokine levels in serum and hypothalamic protein lysates were measured using Luminex MagPix instrument and mouse ProcartaPlex 7 plex (Affymetrix eBioscience, San Diego, CA). Hormone assays were performed by the University of Virginia, Ligand Core. The University of Virginia Center for Research in Reproduction Ligand Assay and Analysis Core is a fee-for-service core facility and is supported in part by the Eunice Kennedy Shriver NICHD/NIH U54-HD28934 Grant. LH was measured by the ultra-sensitive mouse LH ELISA, an in-house method. The capture monoclonal antibody (anti-bovine LH beta subunit, 518B7) is provided by Janet Roser, University of California. The detection polyclonal antibody (rabbit LH antiserum, AFP240580Rb) is provided by the National Hormone and Peptide Program (NHPP). HRP-conjugated polyclonal antibody (goat anti-rabbit) is purchased from DakoCytomation (Glostrup, Denmark; D048701-2). Mouse LH reference prep (AFP5306A; NHPP) is used as the assay standard. Intra-assay coefficient of variation is $2.2 \%$ and inter-assay coefficient of variation is $7.3 \%$ at the low end of the curve. Functional sensitivity is $0.016 \mathrm{ng} / \mathrm{ml}$. FSH was assayed by RIA using reagents provided by Dr. A.F. Parlow and the National Hormone and Peptide Program, as previously described (46). Mouse FSH reference prep AFP5308D was used for assay standards. Steroid hormone levels were analyzed using validated commercially available assays, information for which can be found on the core's website: http://www.medicine.virginia.edu/research/institutes-andprograms/crr/lab-facilities/assay-methods-page and reported in Haisenleder et al. (47). Limits of detection were $2.4 \mathrm{ng} / \mathrm{ml}$ for $\mathrm{FSH}, 3 \mathrm{pg} / \mathrm{ml}$ for estradiol, and $10 \mathrm{ng} / \mathrm{dL}$ for testosterone. Intra- and inter-assay coefficients of variation were $6.9 \% / 7.5 \%$, $6.0 \% / 11.4 \%$, and $4.4 \% / 6.4 \%$ for the $\mathrm{FSH}$, estrogen (E2) and testosterone $(\mathrm{T})$, respectively. Ten animals per group were used for each hormone analysis. Statistical differences in hormone levels between Ctr and HFD groups were determined by Student's T-test, and Tukey-Kramer HSD for multiple comparisons using JMP software (SAS Institute; Cary, North Carolina).

\section{Flow Cytometry}

Antibodies used for flow cytometry, immunohistochemisty and western blotting are listed in Table 1. Microglial activation and immune cell influx into the hypothalamus and prefrontal cortex were characterized as previously described (48). Tissues from the hypothalamus and cortex from each mouse was processed separately as part of a 5-mouse cohort per group, with each experiment repeated 3 times. In brief, mice were perfused with ice cold PBS, brains rapidly removed and hypothalami and prefrontal cortex cell suspensions were generated by mechanical dissociation and applied to a discontinuous $1.03 / 1.088$ percoll gradient. Cells were collected from the interface, blocked with anti-CD16/CD32 (1:300, 553141, BD Biosciences, San Jose, CA), and incubated with anti-CD45 APC-eFluor $\mathbb{R} 780$ (1:300, 470451, eBioscience, San Diego, CA) and anti-CD11b PerCPCyanin5.5 (1:300, 45-0112, eBioscience, San Diego, CA) in PBS, $5 \%$ EDTA, 0.4\% BSA. Sytox ${ }^{\mathrm{TM}}$ Green dead stain $(30 \mathrm{nM}, \mathrm{S}$ 34860, ThermoFisher, Chino, CA) was used to exclude dead cells and flow analysis performed using BD LSR II Flow Cytometer. Results were analyzed using FlowJo software (Tree Star, Inc.) and statistical differences were determined by Student's T-test and Tukey's posthoc test.

TABLE 1 | Antibodies.

\begin{tabular}{|c|c|c|c|}
\hline Antibody & Species & Dilution & Provider, cat \# and RRID \\
\hline GFP & chicken & $1: 5,000$ & Abcam, ab13970; AB_300798 \\
\hline lba-1 & rabbit & $1: 300$ & Wako, 019-19741; AB_839504 \\
\hline PSD-95 & rabbit & $1: 2,000$ & Cell Signaling, 3409; AB_1264242 \\
\hline $\begin{array}{l}\text { Synaptophysin } \\
\text { (SYPH) }\end{array}$ & rabbit & $1: 1,000$ & Cell Signaling, 4329; AB_1904154 \\
\hline MAP2 & chicken & $1: 5,000$ & Abcam, ab5392; AB_2138153 \\
\hline $\mathrm{GnRH}$ & rabbit & $1: 1,000$ & $\begin{array}{l}\text { ThermoFisher, PA1-121; } \\
\text { AB_325077 }\end{array}$ \\
\hline$\beta$-tubulin & rabbit & $1: 1,000$ & $\begin{array}{l}\text { Santa Cruz Biotechnology, } \\
\text { sc-9104; AB_2241191 }\end{array}$ \\
\hline $\begin{array}{l}\text { CD45 } \\
\text { APC-eFluor } \\
780\end{array}$ & rat & $1: 300$ & $\begin{array}{l}\text { eBioscience, 47-0451 (clone } \\
\text { 30-F11), AB_1548781 }\end{array}$ \\
\hline $\begin{array}{l}\text { CD11b } \\
\text { PerCP-Cy5.5 }\end{array}$ & rat & $1: 300$ & $\begin{array}{l}\text { eBioscience, 45-0112 (clone } \\
\text { M1/70), AB_953558 }\end{array}$ \\
\hline
\end{tabular}

Bold indicates: RRID, RESEARCH RESOURCE IDENTIFIERS (RRIDs) number. 


\section{Histological Analyses and Immunohistochemistry}

Following Ctr or HFD mice were anesthetized, perfused with $20 \mathrm{ml} \mathrm{PBS}$ and $20 \mathrm{ml} \mathrm{4 \%}$ paraformaldehyde; and tissues collected. Brains were fixed in $4 \%$ paraformaldehyde, embedded in paraffin, and cut to $20 \mu \mathrm{m}$. Slides were deparaffinized in xylene and rehydrated. Antigen unmasking was performed by heating for $10 \mathrm{~min}$ in a Tris-EDTA- $0.3 \%$ Triton $\mathrm{X}$ and endogenous peroxidase was quenched by incubating for $10 \mathrm{~min}$ in $0.3 \%$ hydrogen peroxide. Slides were then blocked with $20 \%$ goat serum and incubated with primary antiserum against GnRH (1:1000 PA1-121, Thermo Sci.) or Iba-1 for microglia (1:300 cat \# 019-19741, Wako) overnight at $4^{\circ} \mathrm{C}$. After PBS washes, slides were incubated with biotinylated goat anti-rabbit IgG (1:300, BA-1000, Vector Laboratories, Burlingame, CA) for $30 \mathrm{~min}$. The Vectastain $\mathrm{ABC}$ elite kit (Vector Laboratories) was used per manufacturer's instructions, after which the $\mathrm{DAB}$ peroxidase kit was used for colorimetric staining. Slides were dehydrated in ethanol and xylene, and cover-slipped with Vectamount (Vector Laboratories).

To visualize GFP-labeled microglia from CX3CR1-GFP mice, and activated macrophages labeled red and microglia labeled green from CCR2-RFP x CX3CR1-GFP mice, after 12 weeks of Ctr or HFD mice were anesthetized, perfused with $20 \mathrm{ml}$ PBS followed by $20 \mathrm{ml}$ of $4 \%$ paraformaldehyde; brains were post-fixed in $4 \%$ paraformaldehyde, frozen in OCT, and cut to $20 \mu \mathrm{m}$ sections using Leica cryostat. Endogenous fluorescence was visualized with Leica microscope.

Hypothalami from GnRH-GFP mice were sectioned to $100 \mu \mathrm{m}$ sections and sections containing organum vasculosum laminae terminalis (OVLT) where GnRH neurons are located, stained for GFP to visualize GnRH neurons. Slides were blocked with $20 \%$ goat serum and incubated with primary antibodies against GFP (1:5000 raised in chicken), at $4^{\circ} \mathrm{C}$ for $48 \mathrm{~h}$. After PBS washes, slides were incubated with FITC/Alexa 488 goat anti-chicken IgG (1:300, Molecular Probes, Eugene, OR) for $30 \mathrm{~min}$. Secondary antibody-only controls were performed to determine antibody specificity. Images were obtained using confocal Leica SP2 microscope. To determine spine density, we followed our established protocol as published before (49-53), with modifications that correspond to previously described procedures for analysis of spines in GnRH neurons $(54,55)$. Spines, that were identified as protrusions from the soma or axon greater than $1 \mu \mathrm{m}$, were counted in the individual neurons where at least 75 um of the axon proximal to soma can be observed using z-stack. The full length of every GFP-labeled GnRH neuron, including soma and the visible length of the main process, was imaged and analyzed using confocal Leica SP2 microscope. Images were encoded for blind analysis. Spine numbers were quantified by scrolling through the series of captured images in the $\mathrm{z}$-stack using LAS $\mathrm{X}$ software and counted for each GFP-labeled GnRH soma and along the $75 \mu \mathrm{m}$ length of axon, at $15-\mu \mathrm{m}$ intervals. We counted at least 3 individual neurons from 4 different sets of mice marked by hand and using Neurolucida program (MBF Bioscience, Vermont).

\section{Western Blot}

Whole cell lysates were obtained from the dissected hypothalami from Ctr and HFD fed mice and after protein determination, the same amount of protein was run on SDS-PAGE, transferred on nitrocellulose membrane and probed for: Postsynaptic density protein 95 (PSD-95; 1:1000, Cat \#3409, Cell Signaling), Synaptophysin (SYPH; 1:1000, cat. \#4329, Cell Signaling), neuronal marker, Microtubule-associated protein 2 (MAP2; 1:5000, cat \#ab5392, Abcam) or $\beta$-tubulin (1:1000, cat \#sc-9104, Santa Cruz Biotechnology). Bands were quantified using ChemiDoc imaging system (Bio-Rad, Hercules, CA).

\section{qPCR Analyses}

Hypothalami were dissected, total RNA extracted and reverse transcribed using Superscript III (Invitrogen, CA). qPCR was performed using an iQ SYBR Green supermix and an IQ5 real-time PCR machine (Bio-Rad Laboratories, Hercules, CA) with primers listed in Table 2 under the following conditions: $95^{\circ} \mathrm{C}$ for $15 \mathrm{~min}$, followed by 40 cycles at $95^{\circ} \mathrm{C}$ for $20 \mathrm{~s}, 56^{\circ} \mathrm{C}$ for $30 \mathrm{~s}$, and $72^{\circ} \mathrm{C}$ for $30 \mathrm{~s}$. The amount of the gene of interest was calculated by comparing the threshold cycle obtained for each sample with the standard

TABLE 2 | Primers.

\begin{tabular}{lll}
\hline Primers & Forward & Reverse \\
\hline Gnrh (GnRH) & CTACTGCTGACTGTGTGTTTG & CATCTTCTTCTGCCTGGCTTC \\
Avp (AVP) & ACACTACGCTCTCCGCTTGT & CGAAGCAGCGTCCTTGC \\
Pomc (POMC) & CAGTGCCAGGACCTCACC & CAGCGAGAGGTCGAGTTG \\
$\|$ (IL-6) & TTCTCTGGGAAATCGTGGAAAT & TCCAGTTGGTAGCATCCATCA \\
Tnfa (TNF $\alpha)$ & ATGTCTCAGCCTCTTCTCATTCC & GCTTGTCACTCGAATTTGAGAA \\
Lif (LIF) & ATGTGCGCCTAACATGACAG & TATGCGACCATCCGATACAG \\
$\| 10($ IL-10) & GCTGGACAACATACTGCTAACC & ATTCCGATAAGGCTTGGCAA \\
B2m (beta-2-microglobulin) & TGACCGGCCTGTATGCTATCCA & CAGTGTGAGCCAGGATATAGAAAGAC \\
Gapdh & TGCACCACCAACTGCTTAG & GGATGCAGGGATGATGTTC
\end{tabular}


curve generated in the same run. Replicates were averaged and divided by the mean value of the beta-2-microglobulin (B2M) housekeeping gene in the same sample using ${ }^{\Delta \Delta} \mathrm{Ct}$ method. Preliminary studies analyzing GAPDH, Ywaz, TBP and $\mathrm{B} 2 \mathrm{M}$ housekeeping genes determined that B2M doesn't change with diet and was subsequently used for normalization. After each run, a melting curve analysis was performed to confirm that a single amplicon was generated in each reaction. Statistical differences in expression between genotypes were determined by Student's T-test, and Tukey's HSD for multiple comparisons using JMP software (SAS Institute; Cary, North Carolina).

\section{RESULTS}

\section{Male Mice on High-Fat Diet Exhibit Lower Levels of Reproductive Hormones}

C57BL/6J male and female mice were placed on high-fat diet (HFD) or control diet (Ctr) 1 week after weaning and their weights measured twice a week. As demonstrated previously (26), male mice gained weight on HFD, while female mice were resistant to diet-induced obesity (DIO) and required longer exposure to HFD to exhibit the same weight difference from mice on control diet (Figure 1A, male; Figure 1B, female). Preliminary studies indicated that females exposed to the HFD for the same length of time as males do not exhibit adverse effects of obesity illustrated bellow, while much longer exposure would increase the risk of confounding our results with negative effects of aging; thus, we opted to keep the females on the HFD until they reach similar weight gain as males. To determine if ovarian estrogens, or other ovarian hormones, play a role in this sex difference, we ovariectomized (OVX) the females at 4 weeks of age and placed them on the HFD and Ctr. OVX females became susceptible to DIO (Figure 1C). These results indicate that ovarian hormones are protective of DIO.

After 12 weeks on their respective diets for males and 19 weeks for unmodified females, when mice on HFD reached 175\% of the weight observed in mice on Ctr diet, we analyzed the adipose tissue deposition by measuring fat depots. We dissected inguinal fat pad from subcutaneous depots, and gonadal fat pad from visceral fat depots, from one side of each animal. Fat pad weights were then compared between Ctr and HFD in both males and females. Weight comparison of fat pads from Ctr and HFD-fed mice indicates that both males (Figure 1D) and females (Figure 1E) deposit fat in both subcutaneous (inguinal) and gonadal fat depots, since fat pads from either depot were heavier in HFD than controls animals. When we compared males to females, Ctr males had significantly heavier subcutaneous fat pads and gonadal fat pads than Ctr females (compare Figures 1D,E). HFD fed males had significantly heavier gonadal fat pads than HFD females. Given the individual weight difference and profound sex differences in size, we also compared fat depots after normalizing fat pad weight to total body weight. There was a significant difference in normalized weight between gonadal fat pads in Ctr males compared to gonadal fat pads in Ctr females, indicating that male mice fed low-fat control

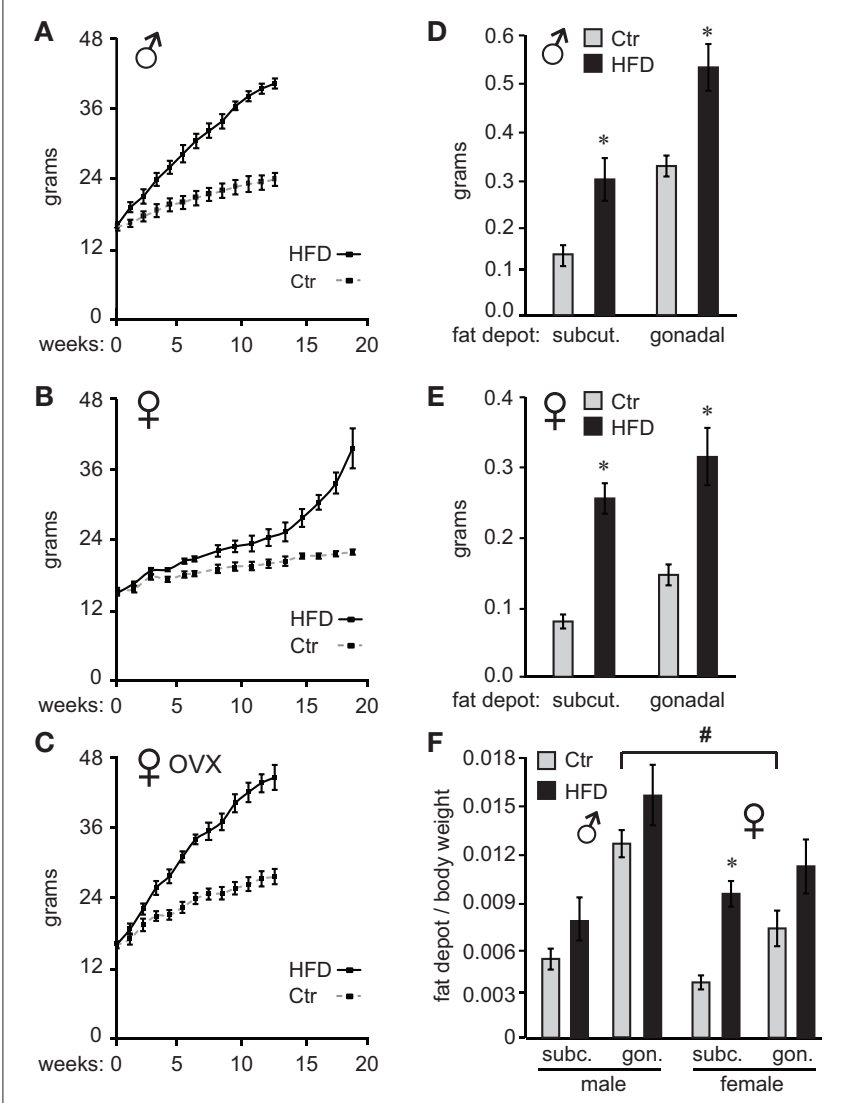

FIGURE 1 | Ovarian hormones provide resistance to diet-induced obesity in female C57Black/6J mice. Ten C57BL/6J mice per group were placed on control (Ctr,10 kcal\%fat, Research Diet) or high fat diet (HFD, 60 kcal\%fat Research Diet) with the same sucrose levels, at 4 weeks of age. Their weights were recorded twice a week (A), males; (B), females. (C), o OVX, female mice were ovariectomized at weaning and one week later, at 4 weeks of age placed on diets. (D), following exposure to their respective diets, mice were sacrificed and subcutaneous (subcut.) fat depots and gonadal fat depots removed from one side of each animal and weights recorded (D), males; (E), females. (F), Subcutaneous (subc.) and gonadal (gon.) fat depot weight from (D,E) was normalized to the whole body weight for each animal. *Indicates significant difference $p<0.05$ between Ctr (gray bars) and HFD (black bars), while \# sign indicates difference between sexes; determined by ANOVA followed by Tukey's HSD test.

diet exhibit higher visceral adiposity than females (Figure 1F, indicated with a pound sign). We did no detect sex differences between other fat depots. Comparison of fat pads between control and HFD revealed preferential fat accumulation in select depots. Significantly, there was a difference in subcutaneous fat pad from HFD female mice compared to subcutaneous fat pad from Ctr females, even after normalizing to the body weight (Figure 1F, asterisk), implying that females preferentially increase adiposity in the subcutaneous depot. Therefore, examination of fat pads may demonstrate that male mice have higher visceral adiposity in control conditions, which corresponds to observations in humans. On the other hand, female obesity may lead to preferential increase in subcutaneous fat, which exhibits less adverse health outcomes (56). 
Following 12 weeks on diets for males and OVX females, which gain weight at the same rate as males, and 19 weeks for unmodified females, we measured gonadotropin hormone and sex steroid hormone levels. Male mice on HFD exhibited 57\% lower luteinizing hormone (LH), 35\% lower follicle-stimulating hormone (FSH), and 40\% lower intra-testicular testosterone levels (Figure 2A). Consequently, HFD males had 50\% fewer sperm in their epididymides (Figure 2A), 22\% lower seminal vesicle weight, which is dependent on the level of testosterone, while testis weight was unaffected (data not shown). Female mice exhibited longer estrous cycles (4.6 days, controls and 6.4 days, HFD), but LH, FSH or estradiol level $\left(\mathrm{E}_{2}\right)$ in diestrus were not significantly changed (Figure 2B). Thus, female mice, although obese as a result of prolonged exposure to HFD, do not exhibit changes in gonadotropin hormone levels. LH and FSH levels in OVX females were significantly higher than LH and $\mathrm{FSH}$ in unmodified females due to the lack of negative feedback (compare Figure 2B and Figure 2C), which confirms

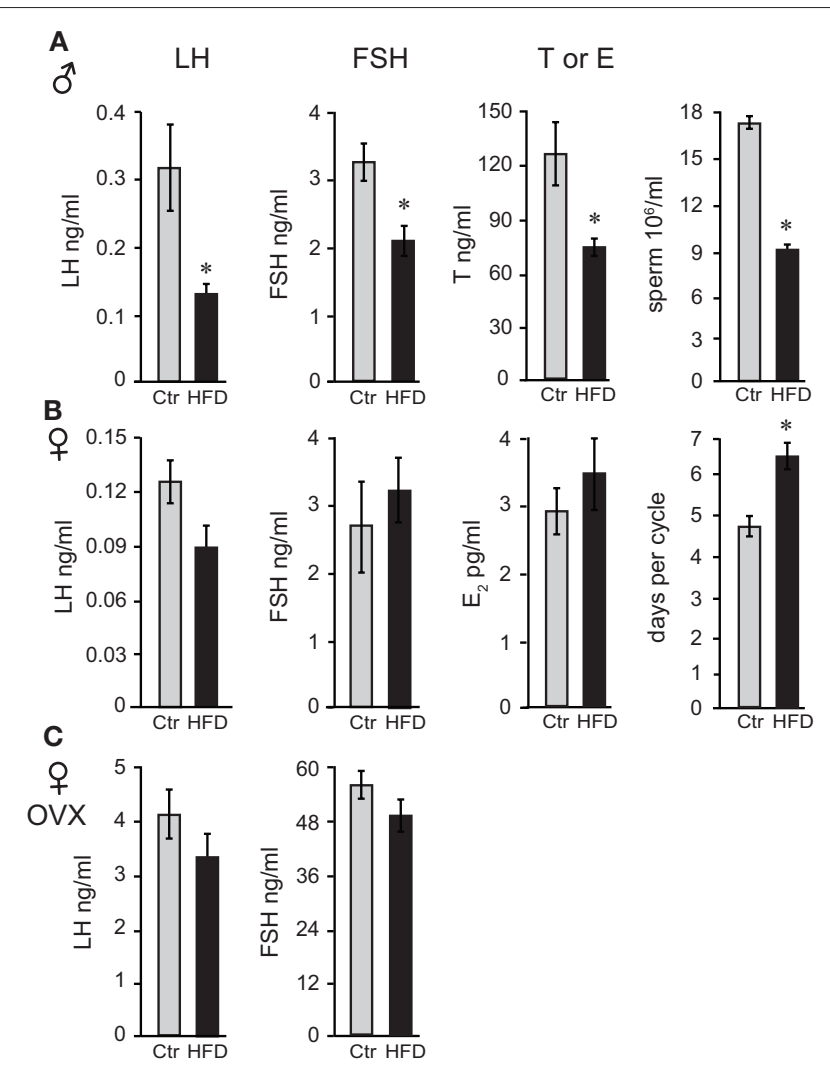

FIGURE 2 | Reproductive hormones are lower in obese male mice, while both unmodified and ovariectomized females are protected from diet-induced changes. Male mice (A) on the HFD have reduced levels of luteinizing hormone $(\mathrm{LH})$, follicle-stimulating hormone $(\mathrm{FSH})$ and intra-testicular testosterone (T), and fewer sperm. Female mice (B) lack changes in LH, FSH, and estrogen $\left(E_{2}\right)$, but exhibit longer estrous cycles. Ovariectomized (OVX) females $\mathbf{( C )}$ are protected from hormonal changes similarly to unmodified females, indicating that the ovarian hormones are dispensable for protection. Differences ( ${ }^{*} p<0.05$ ) between control (Ctr, gray bars) and high fat diet (HFD, black bars) were determined by Student's $T$-test followed by Tukey's HSD test. that ovariectomy was successful. However, neither LH nor FSH in OVX females were affected by diet (Figure 2C). Thus, there are profound sex differences and females are resistant to diet-induced changes in reproductive hormones. Additionally, these results demonstrate that ovarian hormones contribute to resistance to obesity, but are not necessary for the protection from hormonal changes exhibited by female mice.

Since LH levels are strictly regulated by GnRH neuropeptide from the hypothalamus, GnRH (Gnrh) expression was analyzed and revealed that male mice on $\mathrm{HFD}$ exhibited $46 \%$ reduced levels of Gnrh mRNA. To analyze specificity of repression,

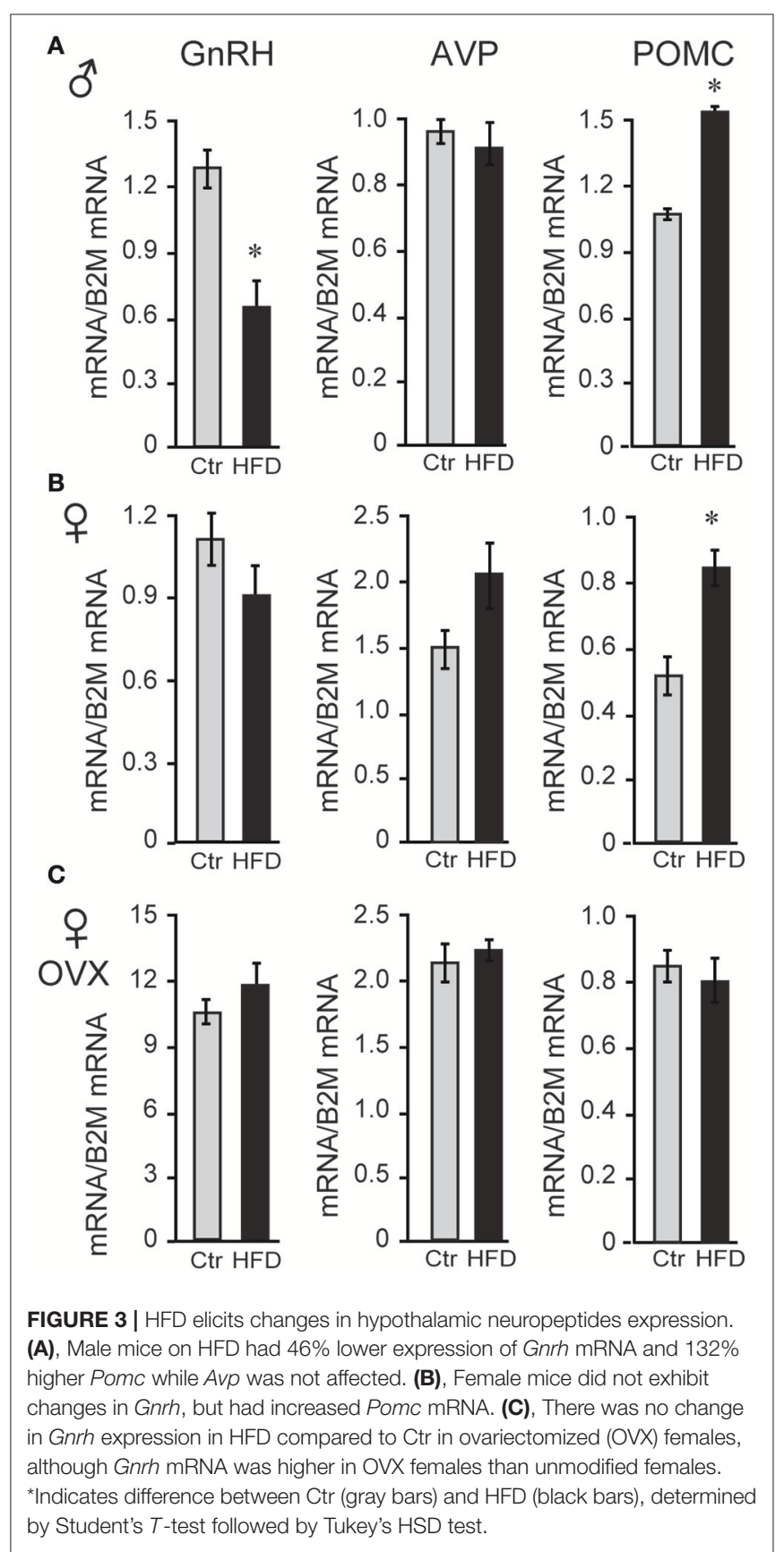




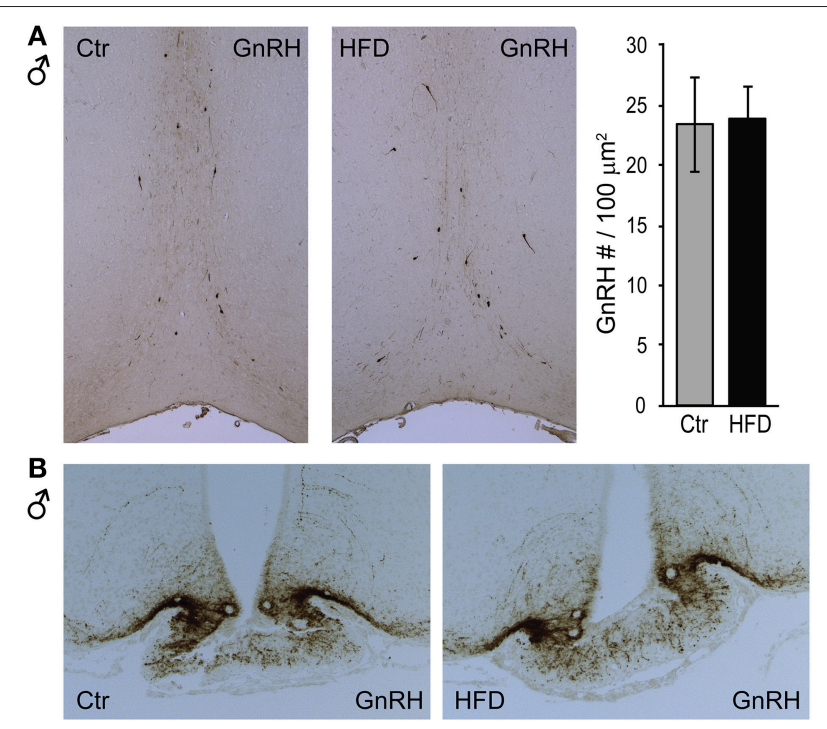

FIGURE 4 | GnRH neuron number or axon targeting is unchanged in DIO mice. Coronal sections of the preoptic area (A, top) and median eminence (B, bottom) from Ctr and HFD fed male mice, were stained with anti-GnRH antibodies. No diet-mediated changes in $\mathrm{GnRH}$ neuron number, nor axon targeting were detected.

additional neuropeptides were assessed, and we determined that Pomc (POMC, proopiomelanocortin) mRNA was increased by $132 \%$, while Avp (arginine vasopressin) mRNA was unchanged (Figure 3A). Neither unmodified or OVX female mice, on the other hand, exhibited diet-induced changes in Gnrh mRNA level, although OVX females exhibited $\sim 10$-fold higher Gnrh mRNA levels compared to unmodified females due to the lack of negative feedback (Figures 3B,C). These results again illustrate sex specific DIO-induced alterations in the neuropeptide gene expression in the hypothalamus, independent of the presence of ovarian hormones.

To determine whether a reduction in Gnrh mRNA levels in male mice stems from fewer GnRH neurons after exposure to HFD, we analyzed GnRH neuron number and detected no difference between diets (Figure 4A). We also detected no difference in response to diet in GnRH neuron axon targeting to the median eminence (Figure 4B). Thus, decrease in Gnrh mRNA levels correlates with the reduction in $\mathrm{LH}$, testosterone and sperm count in male mice following HFD.

\section{Sex-Specific Differences in Inflammatory Cytokines in the Circulation and the Hypothalami of HFD-fed Mice}

Obesity is characterized by hyperleptinemia, hyperinsulinemia, hyperlipidemia, hyperglycemia, and chronic inflammation. Significant effort has been devoted to determine the effects of increased leptin, insulin, fatty acids, or glycose on GnRH neuronal function without clear outcomes (13). We analyzed inflammatory cytokine levels following DIO in our mice and determined that inflammatory cytokines were elevated in the

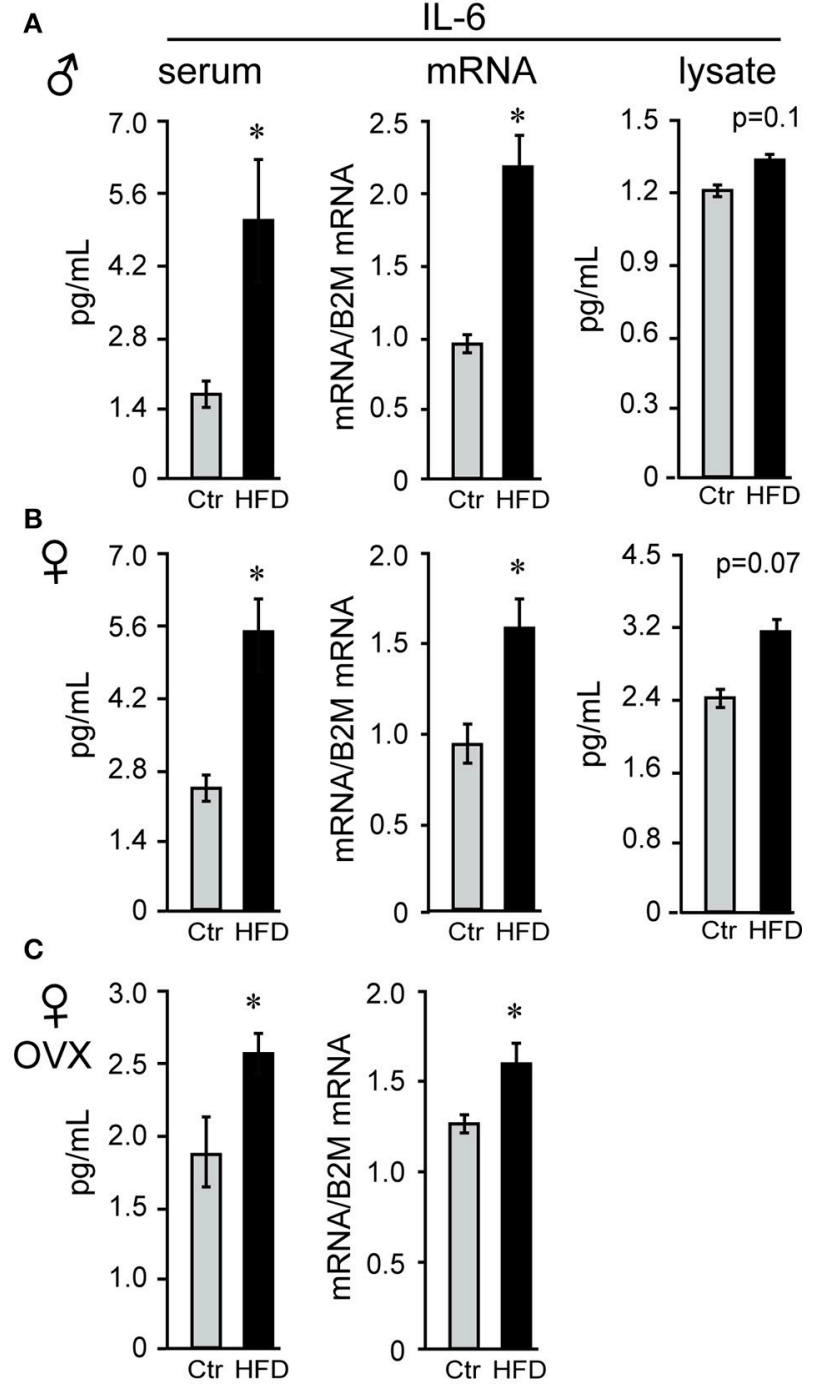

FIGURE 5 | Interleukin-6 (IL-6) is increased in the serum and the hypothalamus of both male and female mice. Following Ctr (gray bars) and HFD (black bars) serum and hypothalami were collected from male (A), unmodified female (B) and ovariectomized (OVX) female mice (C). Cytokine levels in serum and hypothalamic protein lysates were measured using Luminex MagPix instrument and mouse ProcartaPlex 7 plex (Affymetrix eBioscience, San Diego, CA), while mRNA was assayed with qPCR. *Indicates significant difference $(p<0.05)$ between diets determined by Student's T-test and Tukey's posthoc comparison.

circulation as well as in the hypothalami of obese mice. There was no difference in serum levels of interleukin-6 (IL-6) between males, unmodified females or ovariectomized females on control diet (compare Figures 5A,B,C), and all three groups exhibited significantly elevated serum IL-6 following HFD. Increased IL6 in the serum of HFD-fed male mice (Figure 5A) was previously demonstrated (57). IL-6 levels were also increased in the hypothalamic lysates, at the protein and mRNA levels, indicating that IL-6 was induced locally in the hypothalami of the DIO mice. Additionally, hypothalamic IL-6 was increased in both male and female mice (Figures 5B,C). However, increased cytokine levels 
A

ชิ

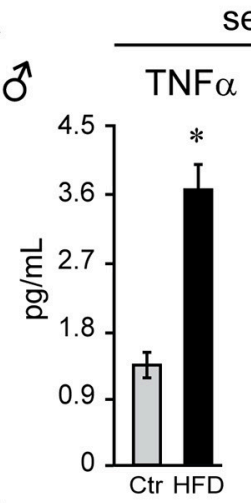

serum

B

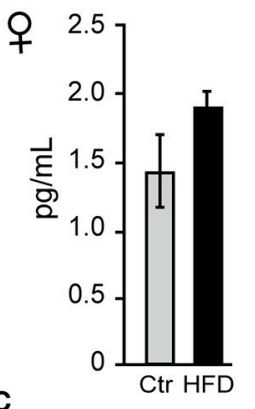

C

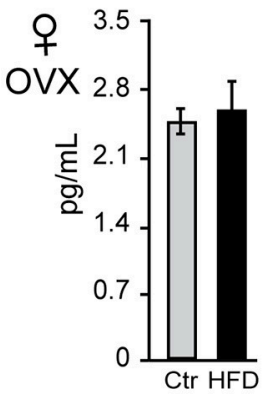

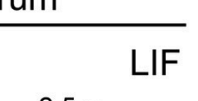
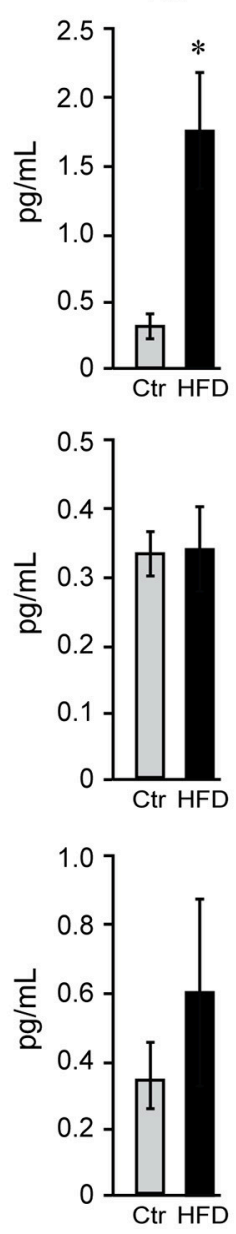
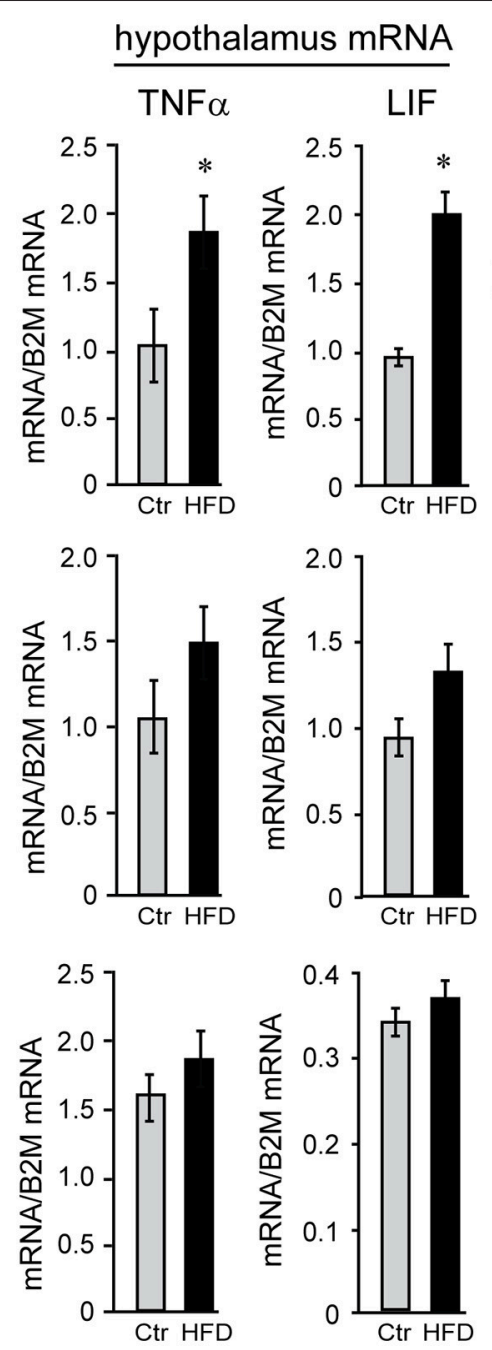

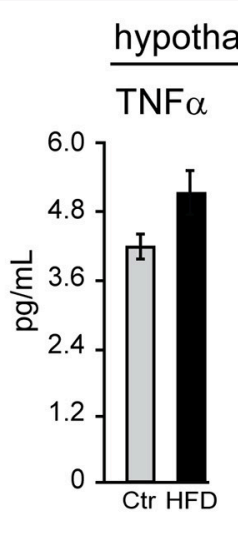

hypothalamus protein
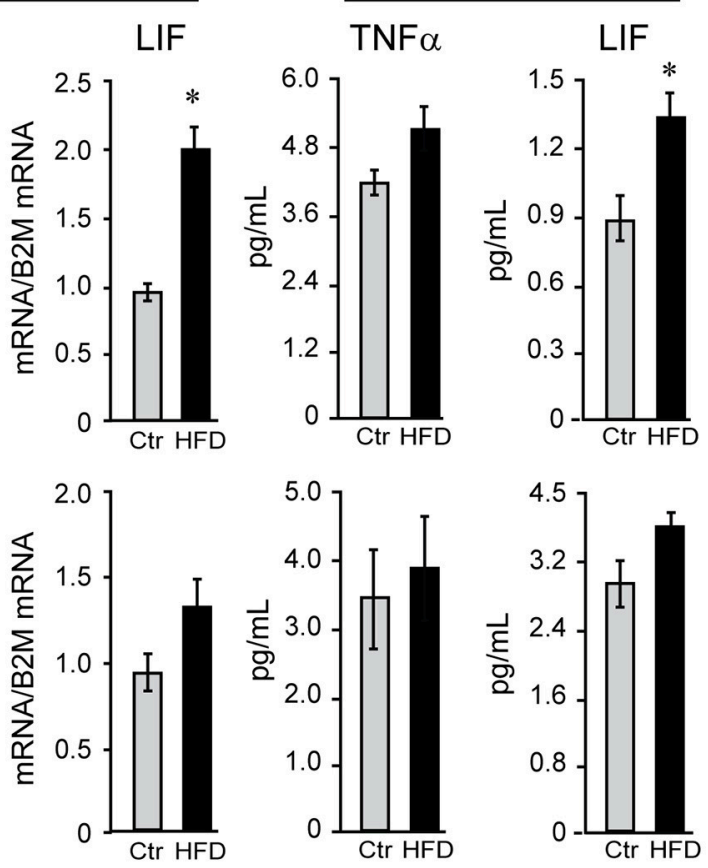

FIGURE 6 | Tumor necrosis factor (TNF) $\alpha$ and leukemia inhibitory factor (LIF) are increased specifically in the male mice regardless of the presence of ovarian estrogens. Serum and hypothalami were collected from male (A), unmodified female (B) and ovariectomized (OVX) female mice (C) following Ctr and HFD. Cytokine levels in serum and hypothalamic protein lysates were measured using Luminex MagPix instrument and mouse ProcartaPlex 7 plex (Affymetrix eBioscience, San Diego, CA), while mRNA was assayed with qPCR. Difference $\left({ }^{*} p<0.05\right)$ between Ctr (gray bars) and HFD (black bars) were determined by Student's $T$-test followed by Tukey's HSD test.

were not detected in the cortex of neither male nor female mice (data not shown), indicating that neuroinflammation is specific for the hypothalamus.

We sought to identify cytokines that may exhibit sex differences in response to HFD. Tumor necrosis factor (TNF) $\alpha$ and leukemia inhibitor factor (LIF) were examined, since shown to increase in DIO (58). There was no sex difference in $\mathrm{TNF} \alpha$ or LIF levels in serum of Ctr males and Ctr unmodified females, while removal of ovaries significantly increased TNF $\alpha$ concentration, but not LIF, in the serum of Ctr OVX females compared to unmodified Ctr females. TNF $\alpha$ and LIF increased specifically in male mice on HFD in the serum (3-fold or $300 \%$ and 4.83 -fold or $483 \%$, respectively), hypothalamic protein levels (112\% and $155.6 \%$, respectively) and mRNA expression levels in the hypothalamus (TNFo, 161\% and LIF, 200\%; Figure 6A), but were not changed in the cortex (data not shown); nor in unmodified or OVX female mice (Figures 6B,C). Therefore, IL6 was increased in both sexes solely in the hypothalami, while $\mathrm{TNF} \alpha$ and LIF are induced specifically in the hypothalami of male mice. Furthermore, while OVX females became susceptible to DIO, they remain protected from the increase in TNF $\alpha$ and LIF inflammatory cytokines in the hypothalamus.

To explain possible protection of female mice, we analyzed anti-inflammatory cytokines. Female mice on Ctr diet exhibit significantly higher concentration of anti-inflammatory IL-10 than Ctr male mice (3.7 pg/ml female, $1.3 \mathrm{pg} / \mathrm{ml}$ male, Figure 7) in the hypothalamus, while IL-10 was below detection limit in the serum in both sexes. Exposure to HFD decreased level of IL-10 protein by $50.2 \%$ and $I l 10$ mRNA by $28 \%$ in male mice; however, HFD increased IL-10 protein to $188 \%$ and Illo mRNA to $165 \%$ 


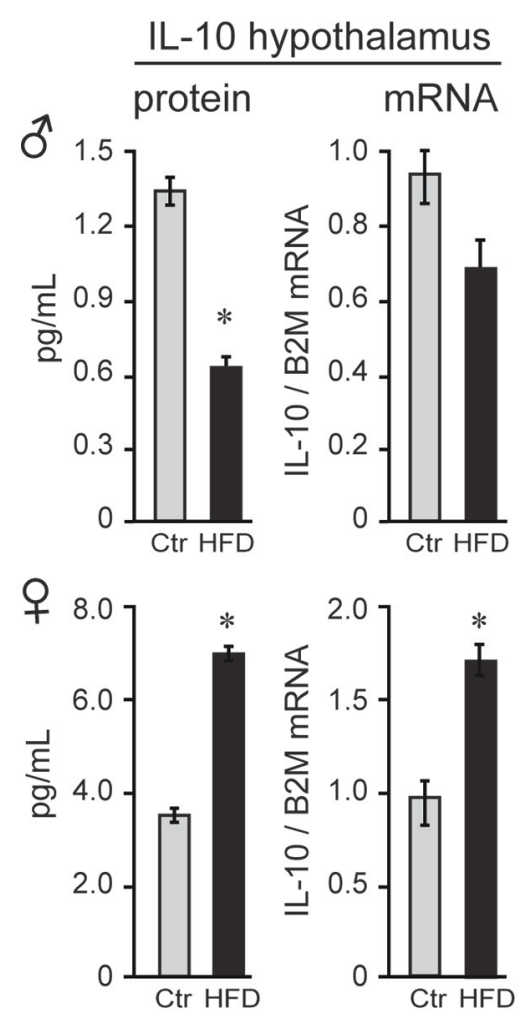

FIGURE 7 | IL-10 is higher in female mice. IL-10 protein was higher in the hypothalami of female mice than male mice, and below detection in the serum in both sexes. After exposure to the HFD, IL-10, both protein and mRNA, decreased in males and increased in females. Statistical significance $\left({ }^{*} p<\right.$ 0.05) between Ctr (gray bars) and HFD (black bars) were determined by Student's $T$-test followed by Tukey's test.

in the female hypothalami (Figure 7). These results indicate that following HFD, inflammatory cytokines are increased, while anti-inflammatory cytokines are decreased in male hypothalami compared to the male mice on control diet. In contrast, female mice on HFD increase anti-inflammatory IL-10 concentration in their hypothalami, while lacking heightened inflammatory response.

\section{Regional Differences in Microglia Activation in the Hypothalamus}

Microglia activation in response to the HFD in the arcuate nucleus of the mediobasal hypothalamus has been demonstrated previously (59-62). Using CX3CR1-GFP mice on Ctr and HFD, we also observed changes from ramified cell body with longer processes, to amoeboid, rounded cells body morphology with retracted processes, indicating activation of the microglia in the arcuate nucleus, (Figure 8A, top). These morphological changes were not observed in the female mice (Figure 8A, bottom). Quantification of CX3CR1-GFP positive cells demonstrated that there is no difference in the number of cells between Ctr males and Ctr females. Exposure to HFD increases the number of GFP-labeled cells in the arcuate nucleus in males, but not in females.

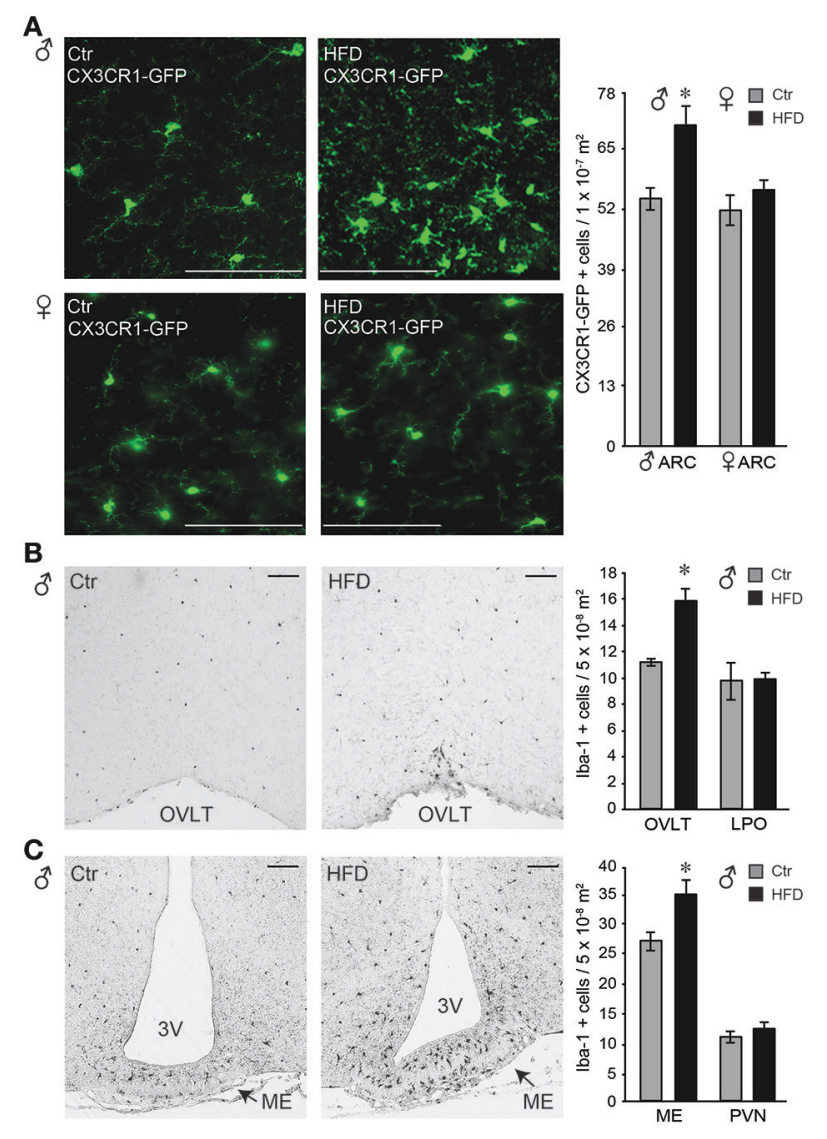

FIGURE 8 | lba-1 positive cells were more abundant in the circumventricular areas of the hypothalamus following HFD in male mice, but not in the female. (A), Microglia, genetically labeled with CX3CR1-GFP, exhibit activated morphology in the arcuate nucleus after HFD specifically in male mice, but not in the female. Quantification determined that there is no difference in microglia numbers in Ctr males compared to Ctr females, or Ctr females compared to HFD females, while male mice on HFD had increased number of CX3CR1-GFP cells in the arcuate nucleus compared to the Ctr mice, indicated with an asterisk. (B), Increased number of lba-1 positive cells around the organum vasculosum laminae terminalis (OVLT) in DIO male mice fed HFD than Ctr mice, but the same numbers in the lateral preoptic area (LPO). (C), Increased lba-1 positive cell number in the median eminence (ME) and arcuate nucleus but not in the paraventricular nucleus (PVN) in male mice on HFD. (A-C), Bar indicates $100 \mu \mathrm{m}$. Difference $\left(^{*}\right)$ between Ctr (gray bars) and HFD (black bars) were determined by ANOVA followed by Tukey's HSD test.

Identification of an increase in cell number in the arcuate nucleus in male mice on HFD prompted investigation of the regional changes in the number of Iba-1 positive cells (Iba-1, is expressed by the microglia in the brain and activated bonederived macrophages). Increased number of Iba- 1 positive cells was detected particularly around the organum vasculosum of the lamina terminalis (OVLT, Figure 8B) in the rostral hypothalamus and in the median eminence (ME) and arcuate nucleus in the mediobasal hypothalamus (Figure 8C), but not in the lateral preoptic area (LPO) or the paraventricular nucleus (PVN). Since PVN is located adjacent to the 3rd ventricle as is the arcuate nucleus, findings that PVN does not exhibit changes in Iba1 positive cell number, while arcuate nucleus does, imply that 


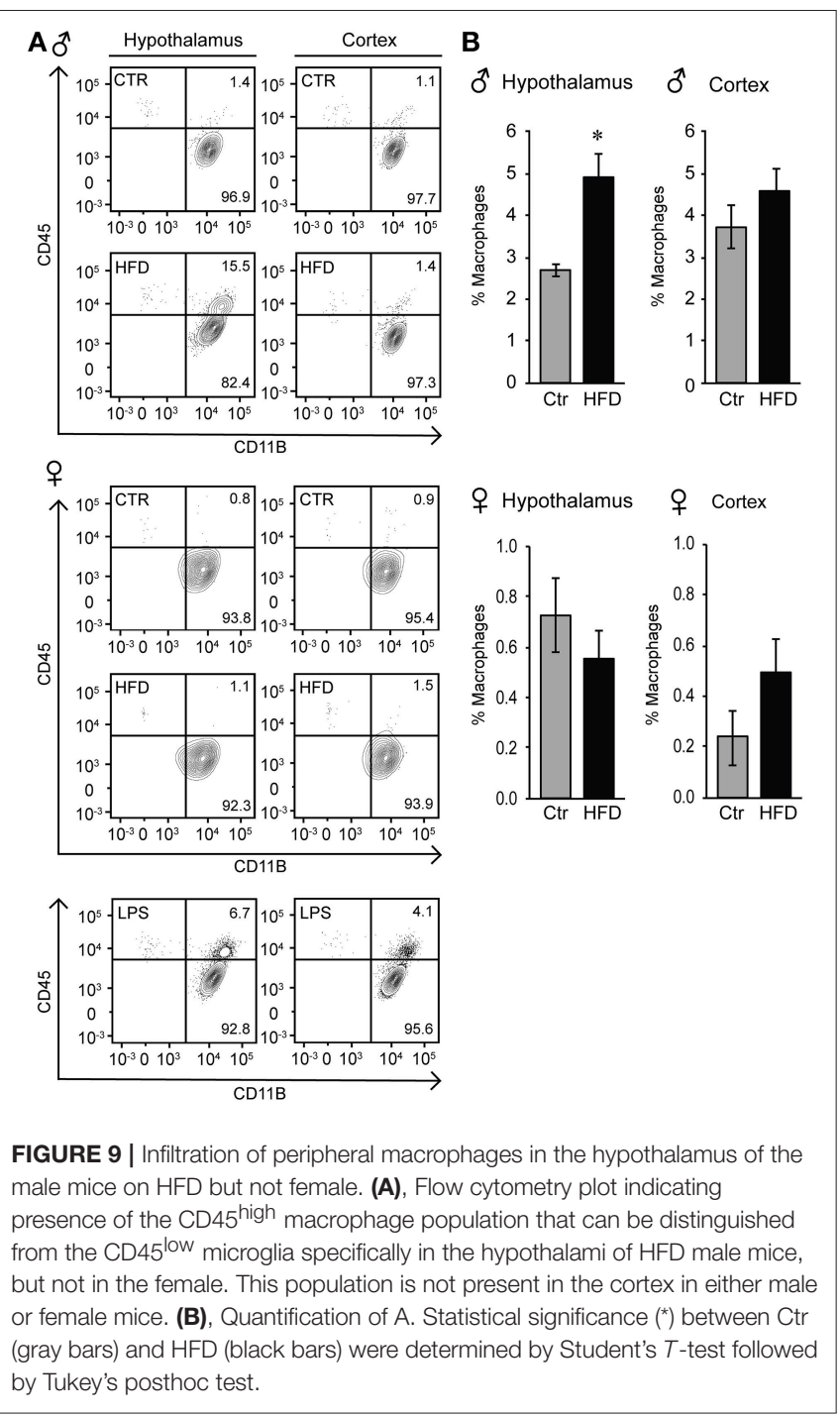

the distance to the 3rd ventricle is not a contributing factor. Consistent with a lack of morphological changes, and lack of changes in the cell number in the arcuate nucleus, female mice did not exhibit any differences in Iba-1 cell number in either ME or OVLT hypothalamic area (data not shown). Therefore, solely in male mice, but not in female mice, HFD elicits an increase in Iba-1 positive cells in the circumventricular areas of the hypothalamus that are known to have a leaky blood-brain barrier.

\section{Infiltration of Peripheral Macrophages to the Hypothalamus of Obese Male Mice}

Given that the increased Iba-1 cell numbers are observed in the areas that contain fenestrated capillaries, and that this increase is not dependent on the distance from the ventricle, we considered two possibilities, that either microglia sense the metabolic changes in the circulation that leads to their activation and proliferation, or that activated monocyte-derived macrophages enter the hypothalamus from the periphery, since increased
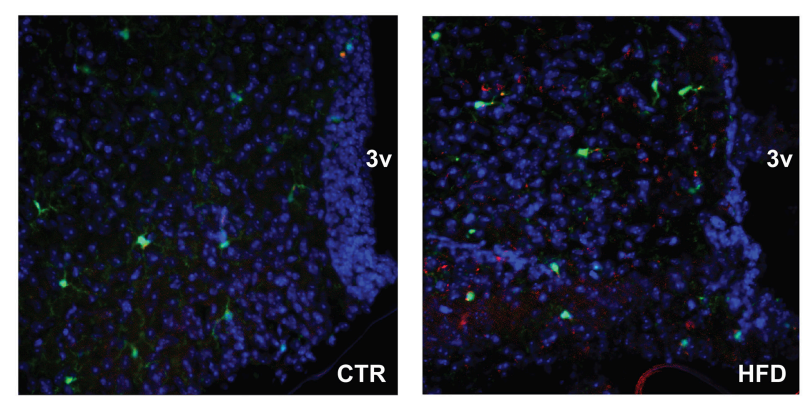

FIGURE 10 | CCR2-positive macrophages localize to the parenchyma of the arcuate nucleus. Doubly fluorescent mice, where activated macrophages are genetically labeled red with CCR2-RFP and resident microglia are labeled green with CX3CR1-GFP, were placed on the control and HFD. Arcuate nuclei of mice on control diet contain only green fluorescence, while arcuate nuclei of mice on HFD contain green fluorescence of resident microglia, and red fluorescence indicating infiltration of peripheral macrophages.

adiposity leads to macrophage activation (33). Microglia and macrophages can be distinguished by flow cytometry from other CNS resident cells due to the presence of CD11b, and can be distinguished from each other by their differential expression of $\mathrm{CD} 45$, since microglia are $\mathrm{CD} 11 \mathrm{~b}+\mathrm{CD} 45^{\text {low }}$ and macrophages are $\mathrm{CD} 11 \mathrm{~b}+\mathrm{CD} 45^{\text {high }}(48,63)$. Hypothalamus and prefrontal cortex were dissected, cells dissociated and subjected to flow analysis, which determined that macrophages are present in the hypothalami of obese male mice, but not in the cortex (Figure 9A). Consistent with the increase in inflammatory cytokines, macrophage recruitment to the hypothalamus is only noted in male mice, and is not observed in the female mice on HFD (Figures 9A,B).

To localize resident microglia and recruited monocytederived macrophages, we generated CX3CR1-GFP and CCR2RFP double transgenic male mice. CX3CR1 is a fractalkine receptor expressed specifically by the microglia in the brain. CCR2 is a chemokine receptor involved in monocyte chemotaxis and infiltration; thus, the presence of RFP expression under CCR2-promoter control would indicate infiltrating activated macrophages. These mice were placed on a Ctr and HFD. In the Ctr, only green-labeled microglia positive for CX3CR1 are present in the arcuate nucleus of the mediobasal hypothalamus (Figure 10, coronal section with 3 rd ventricle on the right side of the image), while in the HFD, RFP-labeled infiltrating macrophages are localized to the brain parenchyma in addition to the GFP-labeled resident microglia. Collectively, these results indicate that peripheral macrophage recruitment to the hypothalamic parenchyma following HFD only occurs in male mice.

\section{Decrease in GnRH Neuron Spines Density in the Hypothalamus of Obese Male Mice}

Macrophage infiltration and elevated inflammatory cytokines in the hypothalamus may lead to synapse elimination (64-66); and subsequent dysregulation of GnRH neurons, which can explain reduced GnRH, LH and testosterone levels in male mice on the HFD. Given that we detected no changes in the number of 


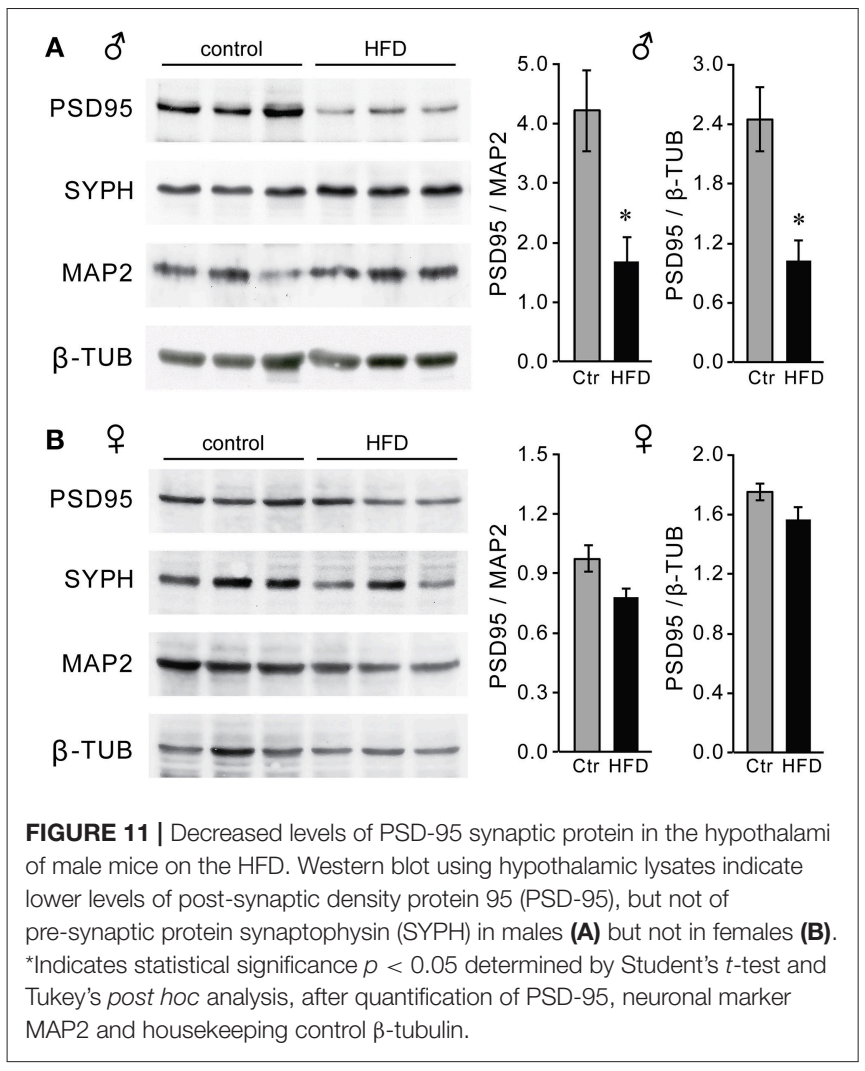

GnRH neurons, we next determined if there are synaptic changes in the hypothalami of HFD male mice and specifically GnRH neurons. Western blot analyses revealed lower levels of excitatory post-synaptic density (PSD) 95 protein in the hypothalami of HFD male mice, while no changes were seen in the overall levels of the pre-synaptic protein synaptophysin (SYPH), usually detected in both excitatory and inhibitory pre-synaptic sites (Figure 11A). In contrast, PSD-95 and synaptophysin levels were unchanged in the hypothalami of female mice on HFD as compared to Ctr females (Figure 11B). Our results show changes in synaptic protein levels in the hypothalamus of male mice that are susceptible to DIO, but not neuro-inflammation resistant female mice.

To assess synapses of specifically GnRH neurons, we placed GnRH-GFP mice (45) on the Ctr or HFD for 12 weeks and analyzed spine density, since changes in the number of spines have been linked to alterations in neuron connectivity (49-53). Spine density was analyzed in the GnRH-GFP neurons of the Ctr and HFD male mice, using the method described previously (54). Spines were identified as protrusions, $1-5 \mu \mathrm{m}$, from the soma or from the proximal axon of these mostly unipolar neurons (67). By scrolling through the z-stack obtained by confocal microscopy, we counted the spines on the soma and along the first $75 \mu \mathrm{m}$ of the length of axon at $15-\mu \mathrm{m}$ intervals. GnRH neurons from male mice on Ctr exhibited the same number of spines on the soma and in each of the $15 \mu \mathrm{m}$ segments as determined before (55). GnRH neurons from HFD male mice exhibit fewer spines, especially in the region of the axon that is $45 \mu \mathrm{m}$ proximal to

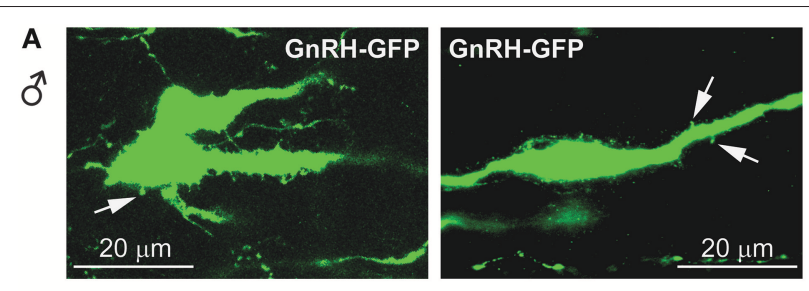

B
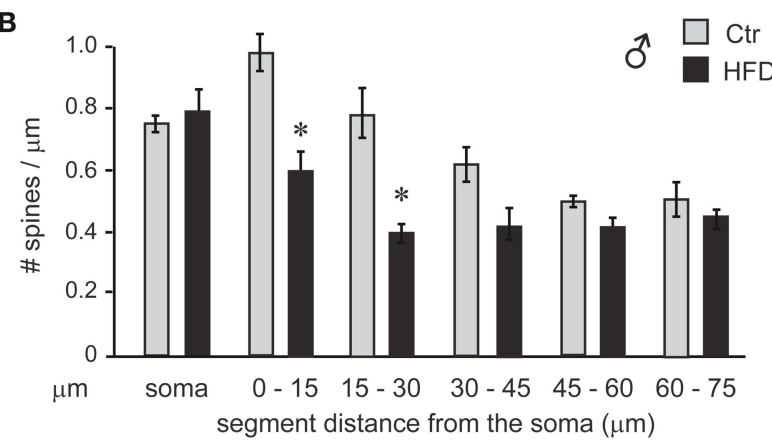

FIGURE 12 | GnRH neuron spine density is lower in male mice on HFD. (A), Coronal sections of the preoptic area in the hypothalamus of the GnRH-GFP mice following control and HFD were stained for GFP (green) to allow for spine count. (B), Spines, identified as protrusions indicated with white arrows in (A), were counted in the soma and in the visible length of the main axon in $15 \mu \mathrm{m}$ intervals, which are indicated in the graph in comparison to the distance from the soma. *Indicates statistical significance $p<0.05$ determined by one-way ANOVA followed by Tukey's post hoc analysis.

soma (Figure 12). Therefore, obese male mice following HFD exhibit neuroinflammation and lower number of spines that may indicate reduced connectivity of the GnRH neurons, which in turn may lead to reduction in $\mathrm{LH}$, testosterone and sperm numbers.

\section{DISCUSSION}

Herein we report several novel findings: (1) we identify sex differences underlying the neuroendocrine response to dietinduced obesity (DIO), and that ovarian hormones protect from DIO, but are dispensable for female resistance to neuropeptide and hormonal changes; (2) we show sex-specific differences associated with inflammatory cytokines, microglial activation and macrophages infiltration in the hypothalamus; in HFD male but not female mice; and (3) we posit a potential mechanism of obesity-induced impairment of hypothalamic function whereby obese males exhibit lower number of synaptic proteins, which may underlie negative effects of obesity on reproductive function.

Sex differences in response to DIO were reported before in mice and in rats (56). Based on these studies and observations in menopausal women it was hypothesized that a lack of estrogen increased adiposity, whereas estrogen replacement diminished it. Increase in adiposity following ovariectomy and removal of ovarian estrogen was observed in rodents (68, 69) and in monkeys (70). Our results concur that ovarian estrogen is protective from DIO, but do not support the assumption that ovarian estrogen is protective from hormonal 
and immunological changes. Hormonal and immune changes have not been examined in response to DIO in unmodified and ovariectomized (OVX) females before. It was assumed that hormonal changes would follow weight gain in females after ovariectomy, however our data indicate that is not the case. We demonstrate that females are protected from hormonal and immune changes regardless of the gonadal status.

Sex differences we observe may stem from variety of other factors, besides ovarian estrogen. In fact, extra-ovarian estrogen may play a role since the Cyp19a1 gene, which encodes for aromatase that mediates estrogen synthesis, is expressed in other tissues, especially the brain and adipose. Brain-produced estrogen may regulate $\mathrm{GnRH}$ neuron function (71), while estrogen synthesis in adipose tissue may regulate deposition in various depots (72). There are also profound sex differences in the immune system (73), metabolic rate and oxidative phosphorylation (74), fat deposition (69) and adipocyte number and size (75), all of which may or may not be dependent on sex steroids, gonadally or locally produced. Our results indicate that sex differences may stem from differences in inflammation or alternate fat deposition, both of which may be interdependent. Females have higher prevalence of autoimmune diseases, but exhibit lower rates of infections and fewer chronic inflammatory diseases (73). Resistance to chronic inflammatory diseases may protect them from obesity-mediated chronic inflammation. Female mice in our study had elevated levels of anti-inflammatory IL-10 in the hypothalamus, which may provide them protection from neuroinflammation. On the other hand, we and others also determined differences in fat deposition $(68,76)$. Our results agree that males have larger visceral fat depots, or gonadal fat pad, with observation in other models and humans, and that premenopausal females preferentially deposit fat into the subcutaneous depot (56). Difference in fat deposition may also be sex steroid dependent (77, 78); and likely provides protection for females, since subcutaneous fat is less adversely correlated with negative effects of obesity than visceral fat. Variances in fat depots, not only absolute adiposity, may impact obesity induced inflammation, since visceral fat, more abundant in males, contains more infiltrating macrophages and higher expression of inflammatory cytokines $(58,79)$ This may increase male propensity for tissue inflammation, in other tissue including the brain.

A few studies have analyzed the effects of the high fat diet (HFD) on the gonadotropin hormones in mice concentrating on females, since they determined that females have longer estrous cycles, findings our results support (26, 80, 81). Due to the significant differences of various mouse strains to DIO, it is difficult to draw a direct comparison between some of these studies and ours, if other studies used a different strain or mixed strain mice (80). Several studies identified significantly different responses to HFD and some strains, such as BALBc and FVB, were surprisingly resistant to DIO (40). In DBA and $\mathrm{C} 57 \mathrm{BL} / 6 \mathrm{~J}$ strains, that are prone to DIO, sex differences vary. Females of the DBA strain are prone to DIO, have lower pregnancy rates and lower Gnrh mRNA (39), while C57BL/6J females are resistant to DIO, as we have also shown herein.
C57BL/6J mice, used in our study, are most often used in DIO studies since they develop insulin resistance and metabolic syndrome that matches human condition $(42,43)$. Reproductive hormones analyses in $\mathrm{DIO} \mathrm{C} 57 \mathrm{BL} / 6 \mathrm{~J}$ mice determined that diestrus females do not exhibit changes in $\mathrm{LH}$, which agrees with our results (81). However, preovulatory levels of LH are lower following HFD, also aligning with the longer estrous cycles in our studies (26). While male mice exhibited lower FSH in both of our studies, employing the new ultra-sensitive assay we also detected decreased LH levels. Therefore, male mice have lower LH, testosterone and sperm count likely due to lower Gnrh mRNA and reduced number of spines in the GnRH neuron.

Lower Gnrh mRNA expression is a consistent finding in mice fed HFD. Repression of Gnrh mRNA in DIO mice has been reported previously [(26, 39), Supplemental Information]. Interestingly, another report analyzing obesity-induced genomewide changes in the brain, detected GnRH as one of the most repressed genes (82). As stated above, acute cytokine infusion in the hypothalamus also represses Gnrh expression (36), suggesting that DIO repression of Gnrh mRNA may be mediated by increased cytokine concentration. Our studies agree that DIO diminishes Gnrh mRNA, and further demonstrate reduction in spine density in GnRH neurons. This may indicate that Gnrh expression may be regulated in an activity-dependent manner $(83,84)$, or alternatively, Gnrh gene may be repressed by cytokines independently of synaptic connectivity. Activitydependent $\mathrm{GnRH}$ gene regulation by afferent neurons has been implied. Hypothalamic factors involved in reproductive function, such as RFamide-related peptide 3 (RFRP-3), a mammalian gonadotropin-inhibitory hormone ortholog; senktide, a neurokinin B receptor agonist; and oxytocin; elicit changes in LH serum levels, by altering both $\mathrm{GnRH}$ secretion and Gnrh transcription (85-87). On the other hand, GnRH neurons express cytokine receptors (88), and Gnrh may be repressed via activation of cytokine receptor signaling pathways.

Reduction in GnRH spine density may indicate lower neuron excitability. A decrease in synapses following HFD was reported previously in the arcuate nucleus in both NPY and POMC neurons, which are widely studied neuronal populations in response to DIO, since they comprise feeding and satiety circuitry in the hypothalamus (89). Specifically, elimination of inhibitory synapses on POMC neurons and excitatory synapses on NPY neurons was described. Reduction in inhibitory synapses may lead to increased POMC expression that was previously reported (89) and is consistent with our findings. Synaptic stripping, reduced levels of synaptic proteins and fewer spines following diet-induced obesity in male C57BL/6J mice were observed in hippocampal neurons as well (90). A decreased performance of HFD mice in cognitive tasks was attributed to the loss of synapses, fewer dendritic spines and a decrease in synaptic proteins in the prefrontal cortex (91). Since number of spines and the levels of PSD-95 synaptic protein are linked to neuronal connectivity, fewer spines and reduced levels of synaptic proteins, may indicate changes in neuronal activity. It was postulated that either estrogen induces changes in a 
number of synapses on POMC neurons, since sex differences were detected in the previous study as well (92); or that leptin is involved in synapse remodeling, since leptin is elevated in obesity and targets POMC neurons (89). Given that POMC and NPY neurons are located in the arcuate nucleus, in light of our results, their synapses may be also eliminated by macrophages or activated microglia. Microglia, brain resident immune cells, are involved in synapse prunning and synapse maturation during development (64) and in the regulation synaptic transmission and activity-dependent structural remodeling in adults (93). Peripheral, monocyte-derived macrophages, however, enter the brain in pathological conditions phagocytosing damaged cells and engulfing synapses $(94,95)$. Obesity-induced damage to POMC neurons that ultimately decreases POMC neuron number was postulated to elicit hypothalamic inflammation (96). We determined that GnRH neurons have fewer spines following HFD, without changes in GnRH neuron number. GnRH neuron cell bodies are located in the preoptic area around the OVLT, which has fenestrated capillaries, which allow for macrophage infiltration. POMC and NPY neurons are located in the arcuate nucleus, which is dorsal to the median eminence that also contains fenestrated capillaries. Thus, specificity in synaptic elimination may stem from the location of the neurons and proximity to the circumventricular areas with leaky blood brain barrier that allows for macrophage infiltration.

Previous studies analyzing effects of obesity identified that neuroinflammation is specific for the hypothalamus and determined that microglia changes morphology specifically in the arcuate nucleus $(59,62)$. In agreement, our studies also failed to detect microglia morphology changes in the cortex and detected them specifically in the hypothalami. Sex differences in microglia activation in response to obesity have also been reported previously (97). Our studies similarly detected morphology changes specifically in the male mice. To assess the regional specificity, we further analyzed other areas besides arcuate nucleus and determined that microglia morphology changes around other circumventricular areas with fenestrated capillaries, such as OVLT. We considered two possibilities, that either microglia sense metabolic changes in the circulation via fenestrated capillaries in circumventricular areas or that increased numbers indicate that peripheral cells which label with anti-Iba- 1 cross into the brain parenchyma specifically in these areas due to the lack of the blood-brain barrier. That prompted us to investigate potential peripheral cells and determine that monocyte-derived macrophages enter the hypothalamus.

Macrophages are functionally dominant cells in obesityinduced chronic inflammation (98). With increased adiposity, proportion of macrophages in adipose tissue increases from 10 to $50 \%$, and they change from less inflammatory M2 phenotype to pro-inflammatory M1 phenotype $(33,58,99,100)$. Elevated macrophage infiltration and cytokines secretion is more highly correlated with visceral adiposity (56). Inflammatory cytokines secreted by the adipose tissue macrophages contribute to the increase in TNF $\alpha$ and IL- 6 in the circulation and chronic inflammation in obese mice and people (34). We determined that activated macrophages infiltrate the hypothalamus in the DIO male mice. Macrophages are recruited to adipose tissue in part via CCR2 interaction with CCL2 that is upregulated in obesity (101). CCR2 is involved in the macrophage recruitment to the liver in obese mice, which contributes to insulin resistance (102). Thus, macrophages activated by increased adiposity infiltrate parenchyma of other tissues. We demonstrated that macrophages recruited to the hypothalamus of obese mice likewise express CCR2. Macrophage switch to pro-inflammatory phenotype with increasing obesity also entails a decrease in the anti-inflammatory IL-10 expression in obese adipose tissue $(32,103)$. Thus, protective role of IL-10 in adipose tissue in DIO has been postulated previously but sex differences were not examined $(104,105)$. We determined that female mice have higher basal levels of IL-10 in the hypothalamus and that obesity exacerbates sex differences since IL-10 is further decreased in obese males in the hypothalamus as well. In the brain, IL-10 is expressed by glial cells (106) and has a protective function (107). We postulate that females, due to the need to handle larger weight changes during pregnancy and lactation, exhibit higher levels of protective anti-inflammatory IL-10 and that increased levels of anti-inflammatory cytokines in female may afford them protection from obesity-induced inflammation.

We demonstrated that male mice, but not females, on HFD exhibit macrophage infiltration to the hypothalamus in addition to the microglia activation, however future studies will identify which of these cells is activated first. Our studies also demonstrate that synaptic proteins are decreased in the hypothalami of obese male mice, and that specifically GnRH neurons have fewer spines and lower Gnrh mRNA expression. Diminished Gnrh mRNA transcription and reduction in GnRH neuron activity may contribute to lower LH levels, reduced testosterone and diminished sperm numbers. Previous studies analyzing crosstalk between metabolism and reproductive function determined that GnRH neurons may integrate obesity-induced changes in glucose directly (108), but changes in insulin (29) and leptin $(28,30)$ are most likely relayed indirectly via neuronal afferents that synapse to GnRH neurons. In this manuscript, we show that GnRH neurons may also mediate the effects of obesity-induced synaptic changes on reproductive function. Future studies will determine if synaptic changes result in changes in the secretion of the neuropeptide that regulates gonadotropin hormone levels and reproduction. Furthermore, we report sex specific changes in neuroinflammation and fat deposition that may explain sex differences in adverse effects of obesity. Future studies will further elucidate sex differences in adipose tissue accumulation and obesity-induced inflammation. Herein, we combine hormonal and immune parameters to identify sex-specific effects of obesity on neuroendocrine function.

\section{AUTHOR CONTRIBUTIONS}

NL: performed most of the experiments; CJ: performed some experiments; $\mathrm{MN}$ : provided expertise in flow analyses and edited the manuscript; IE: provided expertise in neuron and dendritic spine count; EW: provided expertise in flow cytometry and edited the manuscript; MJC: provided expertise in microglia biology, supplied transgenic mice used in the study and revised 
the manuscript; DC: conceived the experiments and wrote the manuscript.

\section{ACKNOWLEDGMENTS}

This research was supported by UCR School of Medicine startup funds to DC; NS071160 and NS072298 to EW; R21AI137830

\section{REFERENCES}

1. The Lancet Public H. Tackling obesity seriously: the time has come. Lancet Public Health (2018) 3:e153. doi: 10.1016/S2468-2667(18)30053-7

2. NCD Risk Factor Collaboration (NCD-RisC) Trends in adult body-mass index in 200 countries from 1975 to 2014: a pooled analysis of 1698 population-based measurement studies with 19.2 million participants. Lancet (2016) 387:1377-96. doi: 10.1016/S0140-6736(16)30054-X

3. Nelson SM, Fleming R. Obesity and reproduction: impact and interventions. Curr Opin Obstetr Gynecol. (2007) 19:384-9. doi: 10.1097/GCO.0b013e32825e1d70

4. Le Thuc O, Stobbe K, Cansell C, Nahon JL, Blondeau N, Rovere C. Hypothalamic inflammation and energy balance disruptions: spotlight on chemokines. Front Endocrinol. (2017) 8:197. doi: 10.3389/fendo.2017.00197

5. Li X, Li X, Fang F, Fu X, Lin H, Gao Q. Is metabolic syndrome associated with the risk of recurrent stroke: a meta-analysis of cohort studies. J Stroke Cerebrovasc Dis. (2017) 26:2700-5. doi: 10.1016/j.jstrokecerebrovasdis.2017.03.014

6. Agusti A, Garcia-Pardo MP, Lopez-Almela I, Campillo I, Maes M, RomaniPerez $\mathrm{M}$, et al. Interplay between the gut-brain axis, obesity and cognitive function. Front Neurosci. (2018) 12:155. doi: 10.3389/fnins.2018.00155

7. Du Plessis SS, Cabler S, McAlister DA, Sabanegh E, Agarwal A. The effect of obesity on sperm disorders and male infertility. Nature Rev Urol. (2010) 7:153-61. doi: 10.1038/nrurol.2010.6

8. Martin JA, Hamilton BE, Ventura SJ, Osterman MJ, Mathews TJ. Births: final data for 2011. Natl Vital Stat Rep. (2013) 62:1-69, 72.

9. Klenov VE, Jungheim ES. Obesity and reproductive function: a review of the evidence. Curr Opin Obstetr Gynecol. (2014) 26:455-60. doi: 10.1097/GCO.0000000000000113

10. Talmor A, Dunphy B. Female obesity and infertility. Best Pract Res Clin Obstetr Gynaecol. (2015) 29:498-506. doi: 10.1016/j.bpobgyn.2014.10.014

11. Mircea CN, Lujan ME, Pierson RA. Metabolic fuel and clinical implications for female reproduction. J Obstet Gynaecol Can. (2007) 29:887-902. doi: 10.1016/S1701-2163(16)32661-5

12. Hill JW, Elmquist JK, Elias CF. Hypothalamic pathways linking energy balance and reproduction. Am J Physiol Endocrinol Metab. (2008) 294:E827832. doi: 10.1152/ajpendo.00670.2007

13. Evans MC, Anderson GM. Neuroendocrine integration of nutritional signals on reproduction. J Mol Endocrinol. (2017) 58:R107-28. doi: 10.1530/JME-16-0212

14. Hohos NM, Skaznik-Wikiel ME. High-fat diet and female fertility. Endocrinology (2017) 158:2407-19. doi: 10.1210/en.2017-00371

15. Manfredi-Lozano M, Roa J, Tena-Sempere M. Connecting metabolism and gonadal function: novel central neuropeptide pathways involved in the metabolic control of puberty and fertility. Front Neuroendocrinol. (2018) 48:37-49. doi: 10.1016/j.yfrne.2017.07.008

16. Stojilkovic SS, Krsmanovic LZ, Spergel DJ, Catt KJ. Gonadotropinreleasing hormone neurons: intrinsic pulsatility and receptor-mediated regulation. Trends Endo Metab. (1994) 5:201-9. doi: 10.1016/1043-2760(94) 90078-7

17. Kaprara A, Huhtaniemi IT. The hypothalamus-pituitary-gonad axis: tales of mice and men. Metabolism (2017) 86:3-17. doi: 10.1016/j.metabol.2017.11.018

18. Coss D. Regulation of reproduction via tight control of gonadotropin hormone levels. Mol Cell Endocrinol. (2018) 463:116-30. doi: 10.1016/j.mce.2017.03.022 and R21AI135500 to MN; and AG048099 to MJC. University of Virginia, Ligand Core is supported by U54-HD28934. The authors thank Dr. Suzanne Moenter for the GnRH-GFP mice. We are grateful to Danielle Worth, Abdullah Madany, Hashini Batugedara, Jordan Koeppen, Jesica Jang, Tyler Landrith, and Kathryn McGovern for technical expertise and thoughtful discussion.
19. Miyata S. New aspects in fenestrated capillary and tissue dynamics in the sensory circumventricular organs of adult brains. FRONT Neurosci. (2015) 9:390. doi: 10.3389/fnins.2015.00390

20. Herbison AE. Control of puberty onset and fertility by gonadotropinreleasing hormone neurons. Nat Rev Endocrinol. (2016) 12:452-66. doi: 10.1038/nrendo.2016.70

21. Goodman RL, Lehman MN. Kisspeptin neurons from mice to men: similarities and differences. Endocrinology (2012) 153:5105-18. doi: 10.1210/en.2012-1550

22. Rivier C, Rivest S. Effect of stress on the activity of the hypothalamicpituitary-gonadal axis: peripheral and central mechanisms. Biol Reprod. (1991) 45:523-32. doi: 10.1095/biolreprod45.4.523

23. Moenter SM. GnRH neurons on LSD: a year of rejecting hypotheses that may have made karl popper proud. Endocrinology (2018) 159:199-205. doi: 10.1210/en.2017-03040

24. Gore AC, Patisaul HB. Neuroendocrine disruption: historical roots, current progress, questions for the future. Front Neuroendocrinol. (2010) 31:395-9. doi: 10.1016/j.yfrne.2010.07.003

25. Wadas BC, Hartshorn CA, Aurand ER, Palmer JS, Roselli CE, Noel $\mathrm{ML}$, et al. Prenatal exposure to vinclozolin disrupts selective aspects of the gonadotrophin-releasing hormone neuronal system of the rabbit. J Neuroendocrinol. (2010) 22:518-26. doi: 10.1111/j.1365-2826.2010. 01973.x

26. Sharma S, Morinaga H, Hwang V, Fan W, Fernandez MO, Varki N, et al. Free fatty acids induce Lhb mRNA but suppress Fshb mRNA in pituitary LbetaT2 gonadotropes and diet-induced obesity reduces FSH levels in male mice and disrupts the proestrous LH/FSH surge in female mice. Endocrinology (2013) 154:2188-99. doi: 10.1210/en.2012-2218

27. Seli E, Babayev E, Collins SC, Nemeth G, Horvath TL. Minireview: metabolism of female reproduction: regulatory mechanisms and clinical implications. Mol Endocrinol. (2014) 28:790-804. doi: 10.1210/me.2013-1413

28. Quennell JH, Mulligan AC, Tups A, Liu X, Phipps SJ, Kemp CJ, et al. Leptin indirectly regulates gonadotropin-releasing hormone neuronal function. Endocrinology (2009) 150:2805-12. doi: 10.1210/en.2008-1693

29. Evans MC, Rizwan M, Mayer C, Boehm U, Anderson GM. Evidence that insulin signalling in gonadotrophin-releasing hormone and kisspeptin neurones does not play an essential role in metabolic regulation of fertility in mice. J Neuroendocrinol. (2014) 26:468-79. doi: 10.1111/jne.12166

30. Ratra DV, Elias CF. Chemical identity of hypothalamic neurons engaged by leptin in reproductive control. J Chem Neuroanatomy (2014) 61-62:233-8. doi: 10.1016/j.jchemneu.2014.05.005

31. Odegaard JI, Chawla A. Pleiotropic actions of insulin resistance and inflammation in metabolic homeostasis. Science (2013) 339:172-7. doi: 10.1126/science. 1230721

32. Lumeng CN, Bodzin JL, Saltiel AR. Obesity induces a phenotypic switch in adipose tissue macrophage polarization. J Clin Invest. (2007) 117:175-84. doi: 10.1172/JCI29881

33. Chawla A, Nguyen KD, Goh YP. Macrophage-mediated inflammation in metabolic disease. Nat Rev Immunol. (2011) 11:738-49. doi: 10.1038/nri3071

34. Olefsky JM, Glass CK. Macrophages, inflammation, and insulin resistance. Annu Rev Physiol. (2010) 72:219-46. doi: 10.1146/annurev-physiol-021909-135846

35. Dozio E, Ruscica M, Galliera E, Corsi MM, Magni P. Leptin, ciliary neurotrophic factor, leukemia inhibitory factor and interleukin-6: class-I cytokines involved in the neuroendocrine regulation of the 
reproductive function. Curr. Protein Peptide Sci. (2009) 10:577-84. doi: 10.2174/138920309789630561

36. Rivest S, Lee S, Attardi B, Rivier C. The chronic intracerebroventricular infusion of interleukin-1 beta alters the activity of the hypothalamicpituitary-gonadal axis of cycling rats. I Effect on LHRH and gonadotropin biosynthesis and secretion.Endocrinology (1993) 133:2424-30. doi: 10.1210/endo.133.6.8243260

37. Feleder C, Refojo D, Jarry H, Wuttke W, Moguilevsky JA. Bacterial endotoxin inhibits LHRH secretion following the increased release of hypothalamic GABA levels. Different effects on amino acid neurotransmitter release. Neuroimmunomodulation (1996) 3:342-51. doi: 10.1159/0000 97294

38. Dondi D, Limonta P, Montagnani Marelli M, Piva F. Mechanism of action of interleukin-1 in modulating gonadotropin secretion. In vivo and in vitro studies. Biol Signals Recept. (1998) 7:55-60. doi: 10.1159/000014528

39. Tortoriello DV, McMinn J, Chua SC. Dietary-induced obesity and hypothalamic infertility in female DBA/2J mice. Endocrinology (2004) 145:1238-47. doi: 10.1210/en.2003-1406

40. Montgomery MK, Hallahan NL, Brown SH, Liu M, Mitchell TW, Cooney GJ, et al. Mouse strain-dependent variation in obesity and glucose homeostasis in response to high-fat feeding. Diabetologia (2013) 56:1129-39. doi: 10.1007/s00125-013-2846-8

41. Farrell GC, Mridha AR, Yeh MM, Arsov T, Van Rooyen DM, Brooling J, et al. Strain dependence of diet-induced NASH and liver fibrosis in obese mice is linked to diabetes and inflammatory phenotype. Liver Int. (2014) 34:1084-93. doi: 10.1111/liv.12335

42. Collins S, Martin TL, Surwit RS, Robidoux J. Genetic vulnerability to diet-induced obesity in the C57BL/6J mouse: physiological and molecular characteristics. Physiol Behav. (2004) 81:243-8. doi: 10.1016/j.physbeh.2004.02.006

43. Wang C-Y, Liao JK. A mouse model of diet-induced obesity and insulin resistance. Methods Mol Biol. (Clifton, NJ) (2012) 821:421-33. doi: 10.1007/978-1-61779-430-8_27

44. Breen KM, Thackray VG, Hsu T, Mak-McCully RA, Coss D, Mellon PL. Stress levels of glucocorticoids inhibit LHbeta-subunit gene expression in gonadotrope cells. Mol Endocrinol. (2012) 26:1716-31. doi: 10.1210/me.2011-1327

45. Suter KJ, Song WJ, Sampson TL, Wuarin JP, Saunders JT, Dudek FE, et al. Genetic targeting of green fluorescent protein to gonadotropin- releasing hormone neurons: characterization of whole-cell electrophysiological properties and morphology. Endocrinology (2000) 141:412-9. doi: 10.1210/endo.141.1.7279

46. Gay VL, Midgley AR Jr, Niswender GD. Patterns of gonadotrophin secretion associated with ovulation. Fed Proc. (1970) 29:1880-7.

47. Haisenleder DJ, Schoenfelder AH, Marcinko ES, Geddis LM, Marshall JC. Estimation of estradiol in mouse serum samples: evaluation of commercial estradiol immunoassays. Endocrinology (2011) 152:4443-7. doi: 10.1210/en.2011-1501

48. Hernandez A, Donovan V, Grinberg YY, Obenaus A, Carson MJ. Differential detection of impact site versus rotational site injury by magnetic resonance imaging and microglial morphology in an unrestrained mild closed head injury model. J Neurochem. (2016) 136:18-28. doi: 10.1111/jnc. 13402

49. Shi Y, Pontrello CG, DeFea KA, Reichardt LF, Ethell IM. Focal adhesion kinase acts downstream of EphB receptors to maintain mature dendritic spines by regulating cofilin activity. J Neurosci. (2009) 29:8129-42. doi: 10.1523/JNEUROSCI.4681-08.2009

50. Dansie LE, Ethell IM. Casting a net on dendritic spines: the extracellular matrix and its receptors. Dev Neurobiol. (2011) 71:956-81. doi: 10.1002/dneu.20963

51. Pontrello CG, Sun MY, Lin A, Fiacco TA, DeFea KA, Ethell IM. Cofilin under control of beta-arrestin-2 in NMDA-dependent dendritic spine plasticity, long-term depression (LTD), and learning. Proc Natl Acad Sci USA. (2012) 109:E442-451. doi: 10.1073/pnas.1118803109

52. Sidhu H, Dansie LE, Hickmott PW, Ethell DW, Ethell IM. Genetic removal of matrix metalloproteinase 9 rescues the symptoms of fragile X syndrome in a mouse model. J Neurosci. (2014) 34:9867-79. doi: 10.1523/JNEUROSCI.1162-14.2014
53. Koeppen J, Nguyen AQ, Nikolakopoulou AM, Garcia M, Hanna S, Woodruff $S$, et al. Functional consequences of synapse remodeling following astrocytespecific regulation of Ephrin-B1 in the adult hippocampus. J Neurosci. (2018) 38:5710-26. doi: 10.1523/JNEUROSCI.3618-17.2018

54. Campbell RE, Han S-K, Herbison AE. Biocytin filling of adult gonadotropinreleasing hormone neurons in situ reveals extensive, spiny, dendritic processes. Endocrinology (2005) 146:1163-9. doi: 10.1210/en.2004-1369

55. Chan H, Prescott M, Ong Z, Herde MK, Herbison AE, Campbell RE. Dendritic spine plasticity in gonadatropin-releasing hormone $(\mathrm{GnRH})$ neurons activated at the time of the preovulatory surge. Endocrinology (2011) 152:4906-14. doi: 10.1210/en.2011-1522

56. Palmer BF, Clegg DJ. The sexual dimorphism of obesity. Mol Cell Endocrinol. (2015) 402:113-9. doi: 10.1016/j.mce.2014.11.029

57. Steppan CM, Lazar MA. Resistin and obesity-associated insulin resistance. Trends Endocrinol Metabol. (2002) 13:18-23. doi: 10.1016/S1043-2760(01)00522-7

58. Weisberg SP, McCann D, Desai M, Rosenbaum M, Leibel RL, Ferrante AW, et al. Obesity is associated with macrophage accumulation in adipose tissue. J Clin Invest. (2003) 112:1796-808. doi: 10.1172/JCI200319246

59. De Souza Cu T, Araujo EP, Bordin S, Ashimine R, Zollner RL, Boschero AC, et al. Consumption of a fat-rich diet activates a proinflammatory response and induces insulin resistance in the hypothalamus. Endocrinology (2005) 146:4192-9. doi: 10.1210/en.2004-1520

60. Valdearcos M, Robblee MM, Benjamin DI, Nomura DK, Xu AW, Koliwad SK. Microglia dictate the impact of saturated fat consumption on hypothalamic inflammation and neuronal function. Cell Rep. (2014) 9:2124-38. doi: 10.1016/j.celrep.2014.11.018

61. Dorfman MD, Thaler JP. Hypothalamic inflammation and gliosis in obesity. Curr Opin Endocrinol Diabetes Obes. (2015) 22:325-30. doi: 10.1097/MED.0000000000000182

62. Valdearcos M, Douglass JD, Robblee MM, Dorfman MD, Stifler DR, Bennett ML, et al. Microglial inflammatory signaling orchestrates the hypothalamic immune response to dietary excess and mediates obesity susceptibility. Cell Metabol. (2017) 26:185-197.e183. doi: 10.1016/j.cmet.2017.05.015

63. Mishra SK, Kumar BS, Khushu S, Singh AK, Gangenahalli G. Early monitoring and quantitative evaluation of macrophage infiltration after experimental traumatic brain injury: a magnetic resonance imaging and flow cytometric analysis. Mol Cell Neurosci. (2017) 78:25-34. doi: 10.1016/j.mcn.2016.11.008

64. Kettenmann H, Kirchhoff F, Verkhratsky A. Microglia: new roles for the synaptic stripper. Neuron (2013) 77:10-8. doi: 10.1016/j.neuron.2012.12.023

65. Mir S, Sen T, Sen N. Cytokine-induced GAPDH sulfhydration affects PSD95 degradation and memory. Mol. Cell (2014) 56:786-95. doi: 10.1016/j.molcel.2014.10.019

66. Ru W, Tang SJ. HIV-associated synaptic degeneration. Mol Brain (2017) 10:40. doi: 10.1186/s13041-017-0321-z

67. Herde MK, Iremonger KJ, Constantin S, Herbison AE. GnRH neurons elaborate a long-range projection with shared axonal and dendritic functions. $J$ Neurosci. (2013) 33:12689-97. doi: 10.1523/JNEUROSCI.0579-13.2013

68. Grove KL, Fried SK, Greenberg AS, Xiao XQ, Clegg DJ. A microarray analysis of sexual dimorphism of adipose tissues in high-fat-diet-induced obese mice. Int J Obesity (2010) 34:989-1000. doi: 10.1038/ijo.2010.12

69. Stubbins RE, Holcomb VB, Hong J, Nunez NP. Estrogen modulates abdominal adiposity and protects female mice from obesity and impaired glucose tolerance. Eur J Nutr. (2012) 51:861-70. doi: 10.1007/s00394-011-0266-4

70. Sullivan EL, Daniels AJ, Koegler FH, Cameron JL. Evidence in female rhesus monkeys (Macaca mulatta) that nighttime caloric intake is not associated with weight gain. Obesity Res. (2005) 13:2072-80. doi: 10.1038/oby. 2005.257

71. Terasawa E. Neuroestradiol in regulation of GnRH release. Horm Behav. (2018). doi: 10.1016/j.yhbeh.2018.04.003. [Epub ahead of print].

72. Rubinow KB. An intracrine view of sex steroids, immunity, and metabolic regulation. Mol Metabol. (2018). 15:92-103. doi: 10.1016/j.molmet.2018.03.001

73. Gubbels Bupp MR. Sex, the aging immune system, and chronic disease. Cell Immunol. (2015) 294:102-10. doi: 10.1016/j.cellimm.2015.02.002 
74. Gaignard P, Frechou M, Liere P, Therond P, Schumacher M, Slama A, et al. Sex differences in brain mitochondrial metabolism: influence of endogenous steroids and stroke. J Neuroendocrinol. (2018) 30:e12497. doi: $10.1111 /$ jne.12497

75. Pallier E, Aubert R, Lemonnier D. Effect of diet and ovariectomy on adipose tissue cellularity in mice. Reprod Nutr Dev. (1980) 20:631-6. doi: 10.1051/rnd:19800404

76. Shulman GI. Ectopic fat in insulin resistance, dyslipidemia, and cardiometabolic disease. $N$ Engl J Med. (2014) 371:1131-41. doi: 10.1056/NEJMra1011035

77. Clegg DJ, Brown LM, Woods SC, Benoit SC. Gonadal hormones determine sensitivity to central leptin and insulin. Diabetes (2006) 55:978-87. doi: 10.2337/diabetes.55.04.06.db05-1339

78. True C, Abbott DH, Roberts CT Jr, Varlamov O. Sex differences in androgen regulation of metabolism in nonhuman primates. Adv Exp Med Biol. (2017) 1043:559-74. doi: 10.1007/978-3-319-70178-3_24

79. Strissel KJ, Stancheva Z, Miyoshi H, Perfield JW II, DeFuria J, Jick Z, et al. Adipocyte death, adipose tissue remodeling, and obesity complications. Diabetes (2007) 56:2910-8. doi: 10.2337/ db07-0767

80. Brothers KJ, Wu S, DiVall SA, Messmer MR, Kahn CR, Miller RS, et al. Rescue of obesity-induced infertility in female mice due to a pituitaryspecific knockout of the insulin receptor. Cell Metab. (2010) 12:295-305. doi: 10.1016/j.cmet.2010.06.010

81. Fernandez MO, Sharma S, Kim S, Rickert E, Hsueh K, Hwang V, et al. Obese neuronal ppargamma knockout mice are leptin sensitive but show impaired glucose tolerance and fertility. Endocrinology (2017) 158:121-33. doi: 10.1210/en.2016-1818

82. Nam KN, Mounier A, Wolfe CM, Fitz NF, Carter AY, Castranio EL, et al. Effect of high fat diet on phenotype, brain transcriptome and lipidome in Alzheimer's model mice. Sci Rep. (2017) 7:4307. doi: 10.1038/s41598-017-04412-2

83. Bao J, Lin H, Ouyang Y, Lei D, Osman A, Kim TW, et al. Activity-dependent transcription regulation of PSD-95 by neuregulin-1 and Eos. Nat Neurosci. (2004) 7:1250-8. doi: 10.1038/nn1342

84. Ebert DH, Greenberg ME. Activity-dependent neuronal signalling and autism spectrum disorder. Nature (2013) 493:327-37. doi: 10.1038/nature11860

85. Grachev P, Li XF, Kinsey-Jones JS, di Domenico AL, Millar RP, Lightman SL, et al. Suppression of the GnRH pulse generator by neurokinin B involves a kappa-opioid receptor-dependent mechanism. Endocrinology (2012) 153:4894-904. doi: 10.1210/en.2012-1574

86. Xiang W, Zhang B, Lv F, Ma Y, Chen H, Chen L, et al. The inhibitory effects of RFamide-related peptide 3 on luteinizing hormone release involves an estradiol-dependent manner in prepubertal but not in adult female mice. Biol Reprod. (2015) 93:30. doi: 10.1095/biolreprod.115.128777

87. Salehi MS, Khazali H, Mahmoudi F, Janahmadi M. Oxytocin intranasal administration affects neural networks upstream of GNRH neurons. $j \mathrm{Mol}$ Neurosci. (2017) 62:356-62. doi: 10.1007/s12031-017-0943-8

88. Jasoni CL, Todman MG, Han SK, Herbison AE. Expression of mRNAs encoding receptors that mediate stress signals in gonadotropin-releasing hormone neurons of the mouse. Neuroendocrinology (2005) 82:320-8. doi: 10.1159/000093155

89. Horvath TL, Sarman B, Garcia-Caceres C, Enriori PJ, Sotonyi P, Shanabrough $\mathrm{M}$, et al. Synaptic input organization of the melanocortin system predicts diet-induced hypothalamic reactive gliosis and obesity. Proc Natl Acad Sci USA. (2010) 107:14875-80. doi: 10.1073/pnas.1004282107

90. Hao S, Dey A, Yu X, Stranahan AM. Dietary obesity reversibly induces synaptic stripping by microglia and impairs hippocampal plasticity. Brain Behav Immunity (2016) 51:230-9. doi: 10.1016/j.bbi.2015. 08.023

91. Bocarsly ME, Fasolino M, Kane GA, LaMarca EA, Kirschen GW, Karatsoreos IN, et al. Obesity diminishes synaptic markers, alters microglial morphology, and impairs cognitive function. Proc Natl Acad Sci USA. (2015) 112:15731-6. doi: $10.1073 /$ pnas. 1511593112

92. Gao Q, Mezei G, Nie Y, Rao Y, Choi CS, Bechmann I, et al. Anorectic estrogen mimics leptin's effect on the rewiring of melanocortin cells and Stat3 signaling in obese animals. Nat Med. (2006) 13:89. doi: 10.1038/nm1525
93. Schafer DP, Lehrman EK, Stevens B. The "quad-partite" synapse: microgliasynapse interactions in the developing and mature CNS. Glia (2013) 61:2436. doi: $10.1002 /$ glia.22389

94. Kim E, Cho S. Microglia and Monocyte-Derived Macrophages in Stroke. Neurotherapeutics (2016) 13:702-18. doi: 10.1007/s13311-016-0463-1

95. London A, Cohen M, Schwartz M. Microglia and monocyte-derived macrophages: functionally distinct populations that act in concert in CNS plasticity and repair. FRONT Cell Neurosci. (2013) 7:34. doi: 10.3389/fncel.2013.00034

96. Thaler JP, Yi CX, Schur EA, Guyenet SJ, Hwang BH, Dietrich MO, et al. Obesity is associated with hypothalamic injury in rodents and humans. J Clin Invest. (2012) 122:153-62. doi: 10.1172/JCI59660

97. Dorfman MD, Krull JE, Douglass JD, Fasnacht R, Lara-Lince F, Meek TH, et al. Sex differences in microglial CX3CR1 signalling determine obesity susceptibility in mice. Nat Commun. (2017) 8:14556. doi: 10.1038/ncomms14556

98. Barnes MA, Carson MJ, Nair MG. Non-traditional cytokines: how catecholamines and adipokines influence macrophages in immunity, metabolism and the central nervous system. Cytokine (2015) 72:210-9. doi: 10.1016/j.cyto.2015.01.008

99. Osborn O, Olefsky JM. The cellular and signaling networks linking the immune system and metabolism in disease. Nat Med. (2012) 18:363-74. doi: $10.1038 / \mathrm{nm} .2627$

100. Hill AA, Reid Bolus W, Hasty AH. A decade of progress in adipose tissue macrophage biology. Immunol Rev. (2014) 262:134-52. doi: 10.1111/imr.12216

101. Weisberg SP, Hunter D, Huber R, Lemieux J, Slaymaker S, Vaddi K, et al. CCR2 modulates inflammatory and metabolic effects of high-fat feeding. $J$ Clin Invest. (2006) 116:115-24. doi: 10.1172/JCI24335

102. Obstfeld AE, Sugaru E, Thearle M, Francisco AM, Gayet C, Ginsberg HN, et al. C-C chemokine receptor 2 (CCR2) regulates the hepatic recruitment of myeloid cells that promote obesity-induced hepatic steatosis. Diabetes (2010) 59:916-25. doi: 10.2337/db09-1403

103. Lumeng CN, DelProposto JB, Westcott DJ, Saltiel AR. Phenotypic switching of adipose tissue macrophages with obesity is generated by spatiotemporal differences in macrophage subtypes. Diabetes (2008) 57:3239-46. doi: 10.2337/db08-0872

104. Fujisaka S, Usui I, Bukhari A, Ikutani M, Oya T, Kanatani Y, et al. Regulatory mechanisms for adipose tissue M1 and M2 macrophages in diet-induced obese mice. Diabetes (2009) 58:2574-82. doi: 10.2337/ db08-1475

105. Nakata M, Yamamoto S, Okada T, Yada T. AAV-mediated IL-10 gene transfer counteracts inflammation in the hypothalamic arcuate nucleus and obesity induced by high-fat diet. Neuropeptides (2017) 62:87-92. doi: 10.1016/j.npep.2016.11.009

106. Ledeboer A, Breve JJ, Wierinckx A, van der Jagt S, Bristow AF, Leysen JE, et al. Expression and regulation of interleukin-10 and interleukin-10 receptor in rat astroglial and microglial cells. Eur j Neurosci. (2002) 16:1175-85. doi: 10.1046/j.1460-9568.2002. 02200.x

107. Strle K, Zhou JH, Shen WH, Broussard SR, Johnson RW, Freund GG, et al. Interleukin-10 in the brain. Crit Rev Immunol. (2001) 21:427-49. doi: 10.1615/CritRevImmunol.v21.i5.20

108. Roland AV, Moenter SM. Regulation of gonadotropin-releasing hormone neurons by glucose. Trends Endocrinol Metab. (2011) 22:443-9. doi: 10.1016/j.tem.2011.07.001

Conflict of Interest Statement: The authors declare that the research was conducted in the absence of any commercial or financial relationships that could be construed as a potential conflict of interest.

Copyright (C) 2018 Lainez, Jonak, Nair, Ethell, Wilson, Carson and Coss. This is an open-access article distributed under the terms of the Creative Commons Attribution License (CC BY). The use, distribution or reproduction in other forums is permitted, provided the original author(s) and the copyright owner(s) are credited and that the original publication in this journal is cited, in accordance with accepted academic practice. No use, distribution or reproduction is permitted which does not comply with these terms. 